\title{
Review of Relationships Between Solar Wind and Ground-Level Atmospheric Electricity: Case Studies from Hornsund, Spitsbergen, and Swider, Poland
}

\author{
S. Michnowski ${ }^{5}$ - A. Odzimek ${ }^{1}$ (D) - N. G. Kleimenova ${ }^{2}$ - O. V. Kozyreva ${ }^{2}$ - M. Kubicki ${ }^{1}$. \\ Z. $\mathrm{Klos}^{3} \cdot$ S. Israelsson ${ }^{4} \cdot$ N. N. Nikiforova ${ }^{6}$
}

Received: 31 December 2019 / Accepted: 3 March 2021 / Published online: 16 April 2021

(C) The Author(s) 2021

\begin{abstract}
This paper reviews individual cases of the relationships between variations of solar wind parameters and variations of the DC vertical atmospheric electric field, $E_{z}$, and current density, $J_{z}$, measured at ground level in the Arctic, at the S. Siedlecki Polish Polar Station Hornsund, Spitsbergen (Svalbard, Norway), and at the mid-latitude S. Kalinowski Geophysical Observatory in Swider (Poland). A considerable number of events from Hornsund confirmed previous observations of regularity of effects related to the station's position against the location of the potential bays of ionospheric convection and polar electrojets, observed in other polar locations, as well as effects of other polar cap current systems. This allowed us to conclude that the physical dependence of ground-level $E_{z}$ and $J_{z}$ on solar wind changes produce measurable effects which do not require statistical analysis to be observed. We can also expect that the dependence does exist, especially in strongly disturbed circumstances, e.g., following solar flares and Earth-directed coronal mass ejections, at middle latitudes. However, further investigations of these physical relationships by this approach are practically almost impossible since a very large number of variable parameters simultaneously affect the recorded lower atmospheric variables. In addition, results of quantitative analysis of predicted and observed effects are not satisfactory. Future research studies require more efficient ways of investigation by theoretical treatment and modelling work using existing and novel observational data besides taking advantage of scientific progress in magnetospheric physics.
\end{abstract}

Keywords Atmospheric electricity $\cdot$ Solar wind-magnetosphere-ionosphere-atmosphere coupling $\cdot$ Ionospheric convection $\cdot$ Substorms $\cdot$ Magnetic storms $\cdot$ Ground-based measurements $\cdot$ Electric field $\cdot$ Electric current $\cdot$ Diurnal variation

N. N. Nikiforova: retired from Schmidt Institute of Physics of the Earth, Russian Academy of Sciences, Bolshaya Gruzinskaya 10-1, Moscow, 123242, Russia-Deceased.

S. Michnowski: retired from Institute of Geophysics, Polish Academy of Sciences, Ksiecia Janusza 64, 01-452, Warsaw, Poland.

A. Odzimek

aodzimek@igf.edu.pl

Extended author information available on the last page of the article 


\section{Article Highlights}

- A few long-lasting and extreme space weather events, such as the magnetic storm of 1-2 March 1989 or the Bastille Day Storm on 14-16 July 2000, have produced significant disturbances in atmospheric electricity parameters at ground-level that led to longtime investigations of the connections between solar wind-magnetosphere-ionosphere coupling and ground-level atmospheric electricity at high and middle latitudes.

- Types of responses in the atmospheric electric field, $E_{z}$, and current density, $J_{z}$, due to coupling of the Earth's magnetosphere and ionosphere with the solar wind, identified on the basis of several dozen case studies from Hornsund in the Arctic and Swider at mid-latitudes, spanned over 1989-2004, have been reviewed.

- Subsequent statistical analysis of average diurnal variations of the atmospheric electric field at both stations over 2004-2011 at different magnetic activity levels have confirmed the observed main types of responses, although their explanation could have been difficult without earlier comprehensive studies of each case.

- Complexity and irregularity of space weather conditions is a hampering factor in the studies of the responses of atmospheric electricity, and quantitative description of these effects remains unsatisfactory. Further research must take into account novel observations and new models.

\section{Introduction}

Research on the relationships between the lower atmosphere electricity and solar wind (SW) variations is still scarce and delayed in comparison with impressive advances in the investigations of the magnetosphere and ionosphere (M-I) coupling with the solar wind. The remarkable increase of the knowledge on the SW-M-I coupling gives now some new possibilities for a more effective study of the SW influence on the vertical component of the atmospheric electric field $\left(E_{z}\right)$ and electric current density $\left(J_{z}\right)$ usually monitored near the Earth's surface. These effects are still insufficiently recognised and understood, despite their potential importance in physical processes involved in weather and climate changes in the lower atmosphere (Willis 1976; Park 1976b; Herman and Goldberg 1978; Tinsley and Heelis 1993; Tinsley 1994, 2000; Burns et al. 1998, 2007; Lam and Tinsley 2016). Further examination of these controversial effects, reported previously in a number of single cases by, for example, Freier (1961), van der Schueren and Koenigsfeld (1963), Olson (1971), Tanaka et al. (1977), Hale and Croskey (1979), D’Angelo et al. (1982), was undertaken, including an attempt to confirm the occurrence of such effects not only at polar and auroral regions but also at lower latitudes at strong $\mathrm{M}-\mathrm{I}$ disturbances. Although some correlations between the SW-M-I and the corresponding atmospheric electricity parameters were preliminarily established as statistically significant in auroral and subauroral Arctic by Matveev et al. (1982), Bandilet et al. (1982a) and others, as reviewed by Apsen et al. (1988), and in the Antarctic by Frank-Kamenetsky et al. (1986), Tinsley (1996) and others, there was still a scarcity of data on relevant physical dependence in individual cases. Moreover, systematic atmospheric electricity observations in the Arctic are nowadays scanty (Odzimek 2019a), while the most developed facilities at the high latitude regions for M-I investigations have been implemented and still in service for a long time (Lester 2008; Gołkowski 2019; Morley 2020, and references therein). 
This paper presents examples of recordings of ground-level electric field, $E_{z}$, and current, $J_{z}$, at Hornsund (Stanislaw Siedlecki Polish Polar Station, Spitsbergen, Svalbard, Norway) in the Arctic, and contemporary middle-latitude atmospheric electricity recordings of these parameters at Swider, Poland (Stanislaw Kalinowski Geophysical Observatory in Otwock-Świder). Both stations are operated by the Institute of Geophysics, Polish Academy of Sciences (PAS). The location of Hornsund as well as many-year recordings at Swider provided an opportunity to obtain interesting data for the studies of the lower atmosphere electrical couplings with the solar wind. A considerable number of individual cases of $E_{z}$ and $J_{z}$ fair-weather variations were found to be in coincidence with various M-I events imposed by the solar wind. They were presented on the background of data from satellite missions, magnetic station networks, ionospheric radars, riometer networks and other sources of data corresponding to concurrent solar wind and M-I changes. This confrontation allowed us to discern some features of the polar and middle latitude $E_{z}$ and $J_{z}$ variations during characteristic SW-M-I changes and space weather events. Various repeatedly occurring effects were noticed and preliminarily examined. The remarkable occurrences at middle latitudes in individual $E_{z}$ reactions to the main phase of magnetic storms, reviewed here, were discovered on the basis of Swider and polar stations recordings. Undisturbed periods or averaged fair-weather $E_{z}$ and $J_{z}$ daily variations at quiet magnetic conditions were used as a reference level. In individual events, the examined amplitudes of $E_{z}$ and $J_{z}$ deviations indicated the response of the $E_{z}$ and $J_{z}$ to SW-M-I changes seen in concurrent magnetospheric and ionospheric data. Findings gathered by this approach show that the ground-level electric measurements can provide new, qualitative information concerning the coupling between the solar wind, magnetosphere, ionosphere and the global circuit of the lower atmosphere, as anticipated by Michnowski (1998), although quantitative description of the effects remains challenging.

The main aim of this paper is to review the studied cases from the perspective of at least three decades of collaboration and research, in order to summarise main findings and consider directions which may bring further progress in the investigation of these phenomena. Additionally, to make the review more complete, we need to recall our research related to electrical activity of the lower atmosphere induced by solid Earth events such as earthquakes, e.g., Nikiforova et al. (2007). We have been particularly inspired by the studies of the electrical effects in solid Earth by Teisseyre (1997), Teisseyre and Nagahama (2001), and by the reports of responses observed in ground-level atmospheric electric field in connection with major earthquakes (Kobylinski and Michnowski 2007, also N. Kitagawa, personal information). Experimental and theoretical research in this direction is under way worldwide, concerning, for example, earthquake precursors. No such effects occurred during the cases analysed here, and further discussion would be beyond the scope of our review.

\subsection{Solar Wind-Magnetosphere-Ionosphere Coupling}

Solar wind (SW) is a highly variable continuous flow of fully ionised plasma consisting of mainly hydrogen and helium nuclei streaming from the Sun with imbedded magnetic field. The average density of the solar wind plasma is $1-10$ particles per $\mathrm{cm}^{3}$ and the plasma carries the interplanetary magnetic field (IMF) of 1-10 nT (e.g., Kuijpers et al. 2015; Borovsky 2020). At impact with the Earth by the interaction with the Earth's dipolar magnetic field, it produces a teardrop-shaped magnetosphere compressed from the side facing the Sun and largely extending anti-sunwards into a magnetotail. In addition, 
Fig. 1 a Sketch of the large current systems generated in the Earth's magnetosphere and ionosphere by the coupling with the solar wind and interplanetary magnetic field. Based on a figure from Kamide and Baumjohann (1993). b Sketch of the magnetospheric and ionospheric currents and distribution of the electric potential of the ionospheric convection at northern polar region-view from the dusk side. The convection potential is imposed on the electric potential generated by lower atmosphere electric circuit (GEC) driven by currents produced by electrified clouds. Arrows indicate of the direction of the current flow: red contour-R1/R2 FAC and GEC currents, brown-R0 FACs, violet-substorm wedge currents (SWC), turquoise-ionospheric Pedersen currents, orange-Hall currents

the electromagnetic radiation from the Sun forms an ionised conducting layer of the ionosphere, from about $60 \mathrm{~km}$ above the Earth's surface. Above the ionosphere, electrons, protons and some heavy ions form the plasmasphere. Still in the inner magnetospheric region of closed magnetic field lines, energetic plasma particles originating from the solar wind are trapped by the geomagnetic field inside the magnetosphere in the regions called radiation or Van Allen belts. Other population of charged particles in the magnetosphere is the plasma sheet extending in the central region of the magnetotail (e.g., Hargreaves 1992). In this complicated configuration of plasma and magnetic field, a system of electric fields and currents is created in the Earth's magnetosphere due to the geomagnetic field structure and its interaction with the solar wind, especially due to process of reconnection of the geomagnetic and interplanetary magnetic field. Coupling with the solar wind is possible even without reconnection when the solar wind pressure pulses impinge on the magnetopause, the boundary layer. A simplified axiometric sketch of the three-dimensional distribution of the magnetic fields and electric currents around our planet in one half of the Northern Hemisphere is shown in Fig. 1a. One basic magnetospheric current is the Chapman-Ferraro current, including the magnetopause current flowing from dawn to dusk on the sunward side and the magnetopause tail current flowing the opposite direction from dusk to dawn. A cross-tail current flows from dawn to dusk in the equatorward plane of the magnetosphere. Another, an inner magnetospheric current driven westwards around the Earth in the equatorial plane is the ring current.

The interaction of the solar wind and the geomagnetic field in the reconnection leads to a cycle of opening and closing of the geomagnetic field lines and transport of the magnetic flux in the magnetosphere (Dungey 1961; Cowley 1995). The initially closed geomagnetic field lines, after reconnecting with the IMF lines at the dayside magnetopause, become open and are swept antisunwards by the solar wind towards the magnetotail and again reconnect in the central plane of the tail becoming closed field lines (not shown in Fig. 1a). The footprints of open geomagnetic field lines at the ionosphere determine the area of polar caps. This cycle also results in the circulation (convection) of the plasma in the magnetosphere with the magnetic field, and both have important consequences for the electrical structure of the magnetosphere and ionosphere due to their coupling and energy transfer from the solar wind (Lester 2003). The expanding-contracting polar cap model is the currently adopted framework for the analysis of change of open magnetic flux in the magnetosphere (Milan 2015, and references therein). In the case when the IMF is directed southwards, as in Fig. 1a, the reconnection takes place in the equatorial area of the dayside magnetopause and larger amounts of solar wind plasma and magnetic flux are transported towards the tail of the magnetosphere, resulting in substorms.

The geomagnetic field lines in the magnetospheric plasma are almost equipotential due to high electrical conductivity along the magnetic lines of force compared to lower conductivities in perpendicular directions. Hence, any created magnetospheric electric fields are projected with little attenuation along these lines down to the ionosphere driving 

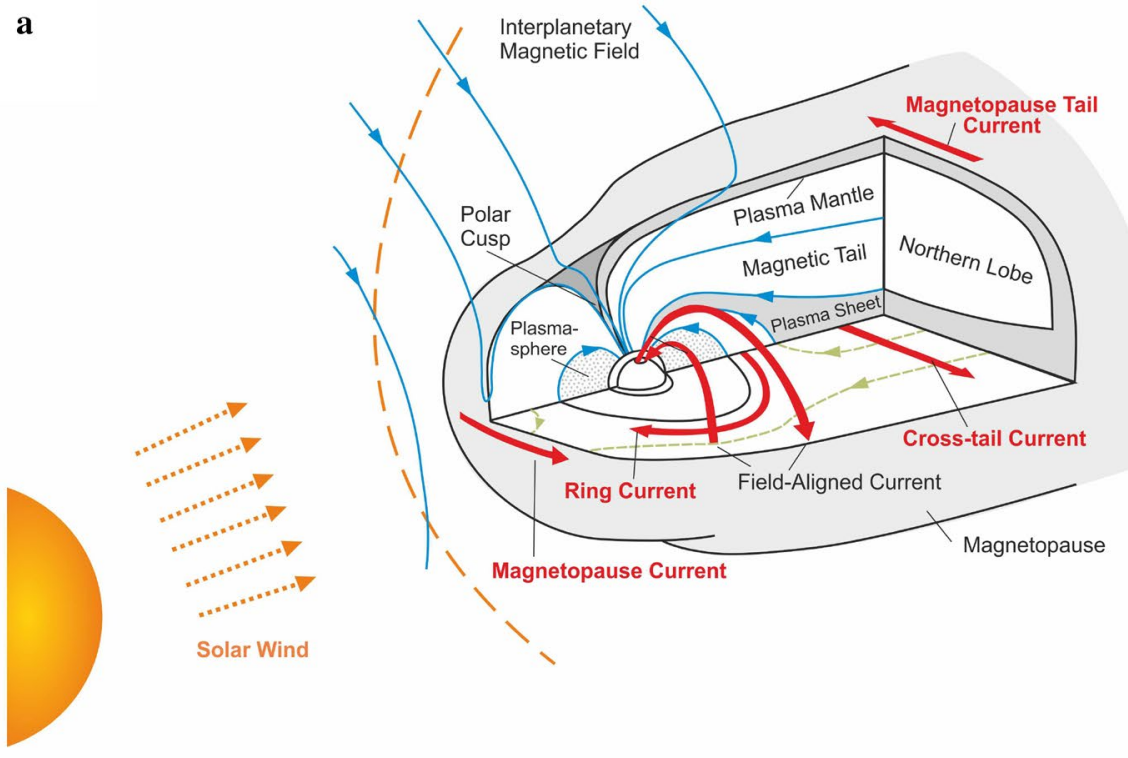

b

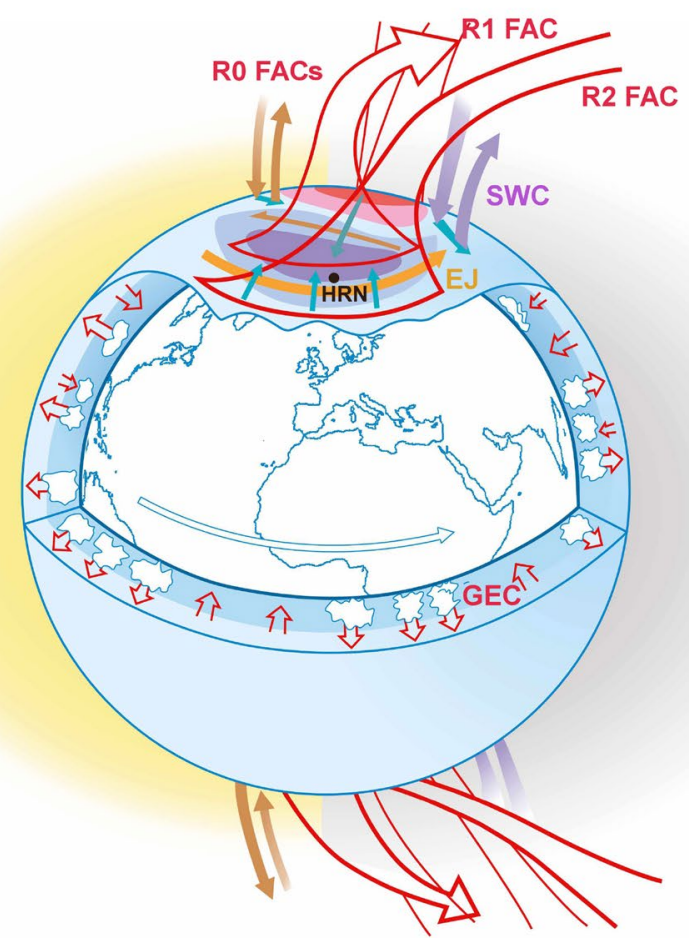

ionospheric plasma convection demonstrated by the corresponding electric potential distribution and creation of large-scale convection fields and currents, also causing frictional heating and plasma instabilities. Bending of the geomagnetic field lines at the ionosphere 
produces Pedersen currents which connect to the magnetopause current by the currents flowing along the geomagnetic field lines called field-aligned currents (FACs), or historically Birkeland currents. As a result, the ionospheric potential distribution mirrors to a very large extent the corresponding large scale SW-M-I coupling processes.

As the ionosphere is closely linked with the magnetosphere via the magnetic lines, the convection of plasma driven by the magnetic reconnection process of the IMF and the geomagnetic field plays important role in the coupling between the solar wind, the magnetosphere and the ionosphere and in modulation of these current systems. In Fig. 1b, the dusk side of the convection potential (negative) is indicated by darkening blue, and a small part of the dawn, positive region that extends at the other side, is marked by pink and reddish. The poleward field-aligned current (white with red contour), one on the dawn and one on the dusk side are called Region 1 (R1) FACs and are located on the so-called open-closed boundary dividing regions of open (polar cap) and closed magnetic field lines. At stronger SW-M-I coupling this boundary is expanding equatorward, shifting also the region of aurora, the light produced from atmospheric particle ionisation and excitation by solar wind particles (auroral oval) to lower latitudes. The R1 FAC in the dusk cell flows out of the ionosphere and R1 FAC in the dawn cell flows into the ionosphere. Field aligned currents connect at their ionospheric end to ionospheric Pedersen currents. There are also ionospheric Hall currents, perpendicular to both geomagnetic field lines and Pedersen currents, the most important Hall currents being the eastern and western electrojets, EJ, flowing in the ionosphere where the electric conductivity is enhanced by the ionisation by energetic particles. On the equatorward side of electrojets there are Region 2 (R2) FACs closing in the partial ring current (not explicitly shown in Fig. 1a). Their flow is opposite to the direction of adjacent R1 currents: into the ionosphere in the dusk sector and out of the ionosphere in the dawn sector (Iijima and Potemra 1976). At the noon side, there is a pair of Region 0 (R0) FAC currents (Iijima et al. 1984). At strong $B_{y}>0$ the outflowing R0 FAC is more intense in Northern Hemisphere, and it is weaker at negative $B_{y}<0$. Opposite takes place in the Southern Hemisphere. At northwards $B_{z}$, i.e. $B_{z}>0$, the R0 FACs expand and become comparable in magnitude to R1 FACs, forming the so-called NBZ current system (Iijima and Potemra 1978). The R0 Birkeland currents are closed in the solar wind in the direction perpendicular to the ecliptic (Kelley and Makela 2002). At the time of a substorm expansion phase, a new current system of two FACs accompanied by ionospheric substorm electrojet is created at night side: the so-called substorm wedge current (SWC) system (Kepko et al. 2015). The SWC current diverts from cross-tail current and flows into the ionosphere at post-midnight and out of the ionosphere at pre-midnight sector. Milan et al. (2017) describe in greater detail and review knowledge of these current systems as well as the geomagnetic disturbances these currents produce, which can be observed at the Earth's surface and further processed into series of indices of geomagnetic activity.

The ionospheric convection potential patterns in the Earth's polar caps, fundamentally important for magnetospheric physics, reflect the convection state of the magnetosphere that is difficult to measure using in situ observations. However, the polar cap potential pattern or field-aligned currents can be estimated using measurements from low Earth orbiting satellites (Hairston et al. 1998), from ground magnetometer networks (Kamide et al. 1981; Kotikov et al. 1993), from HF ionospheric radars, e.g., SuperDARN (Chisham et al. 2007), or from a combination of these data using assimilative techniques (Richmond 1992). An even simpler measure of the magnetospheric and ionospheric convection state can be obtained from the transpolar voltage, or cross-polar cap potential, $\Phi_{\mathrm{PC}}$, that is, the difference between the maximum and the minimum potential in one hemisphere (Raeder and 
Lu 2005). An insight into the cross-polar cap potential is provided by the behaviour of the interplanetary electric field, $E_{\mathrm{SW}}$, and solar wind dynamic pressure rate growth $\left(\mathrm{d} P_{\mathrm{SW}} / \mathrm{d} t\right)$ which appears to be the second most important factor (Troshichev et al. 2007). Observations, theory and modelling indicate that as the geo-effective component of the interplanetary electric field increases from typical values, the electric potential across the polar cap first increases linearly up to about $100 \mathrm{kV}$, and then asymptotes to a limiting value that lies typically between 160 and 250 kV (Hill et al. 1976; Siscoe et al. 2002; Kivelson and Ridley 2008). The polar cap potential difference and total R1 currents are considered intrinsic parameters of the SW-M-I coupling.

Ionospheric electric fields, as demonstrated by Volland (1972), Park (1976a), Park and Dejnakarintra (1977), Bostrom and Fahleson (1977), Roble and Hays (1979), Matveev et al. (1981), Morozov and Troshichev (2008) and others, map downwards to the lower atmosphere where they become part of the measured atmospheric electric field $E_{z}$. At large horizontal spreading of the ionospheric fields, the vertical component of this field near the ground follows the overhead ionosphere potential. The electric fields observed at ground level with simultaneously measured magnetic field are often able to provide, in a broad frequency range, some supplementary information about the disturbances in M-I caused by the solar wind. Sometimes, they may belong to geomagnetic pulsations in the form of magnetohydrodynamical (MHD) waves (Leonovich and Mazur 1990) as investigated by, for example, Zhulin et al. (1977), Kleimenova et al. (1992, 1996). Although the magnetic and electric fields are merely two aspects of the same wave, the independent measurements of them both are needed, at least for the very long-period waves, of frequency less than 3 $\mathrm{mHz}$ (Turski 1996).

Ionising energetic particles from the solar wind affect the ionosphere (Pfaff 2012) and sometimes the lower atmosphere below (Nicoll and Harrison 2014; Mironova et al. 2015). Auroral particle precipitation ionises the high latitude atmosphere and produces heat which can be transferred from the magnetosphere down to the ionosphere. Topics related to energetic particles and auroras in the geospace have been recently reviewed by Dorman (2019), and the magnetosphere as a complex system of fields and particles and its role in the Earth system has been lately reviewed by Borovsky and Valdivia (2018). Galactic cosmic ray (GCR) particles, modulated by solar wind on its way in the interplanetary space, are the main source of atmospheric ionisation in the stratosphere and troposphere globally (Bazilevskaya et al. 2008). The time and spatial distribution of the ionisation changes is complicated, depending on the GCR energy spectrum and the geomagnetic field. The galactic cosmic radiation is occasionally enhanced by solar energetic particle events (SEP) coming from solar flares. The SEP may reach the troposphere and occasionally even ground level in the so-called ground level events (GLE) (Cliver et al. 1982; Gopalswamy et al. 2012). Energetic particles of the galactic cosmic rays and energetic particles of solar origin change the conductivity and its vertical profile in the lower atmosphere.

Both kinds of the solar wind influence, by altering the electrical state of the ionosphere and the lower atmosphere, are expected to affect the recorded atmospheric electric field at the Earth's surface, $E_{z}$, and electric current density, $J_{z}$, which both are simultaneously a part of the global lower atmosphere electric current circuit, GEC (Wilson 1909, 1921; Markson 1978; Raina 1991; Bering 1995; Bering et al. 1998; Michnowski 1998; Rycroft et al. 2000, 2008; Williams 2009; Williams and Mareev 2014).

Although the ionospheric potential distribution and atmospheric conductivity variations depend intrinsically on solar wind changes, the response of $E_{z}$ and $J_{z}$ to them is still not much explored and known, in contrast to the spectacular progress in the investigations of the magnetosphere and ionosphere's dependence on the solar wind and its magnetic and 
electric field changes. Numerous processes are involved both in the modification of the magnetosphere by the solar wind and the effects of the magnetosphere and ionosphere on the lower-atmosphere $E_{z}$ and $J_{z}$. Studies of the SW effects on these parameters are therefore complicated and require multidisciplinary treatment.

In the lower atmosphere of polar regions, in addition to local meteorological noise and global electric circuit effects present at the ground level everywhere, the variable ionospheric electric potential distributions as well as the lower atmosphere conductivity vertical profiles are very active. Observed variability of the investigated effects is intricate also by the fact that the changeable patterns of the ionospheric potential and particle fluxes in the polar atmosphere remain in Sun-aligned geomagnetic coordinates, while the ionosphere point above the station rotating with the Earth runs a trajectory. Thus, at crossing the equipotential lines the values of the ionospheric potential above the station indicate not only temporal variations in the ionosphere potential but also its spatial changes along the scanned trajectory. In cases of quasi-stationary state of the ionosphere, when its electric potential distribution does not much change in time, the potential of the point above the station is, to some extent, able to be indicative of the electric potential distribution along the scanned trajectory. On the contrary, at sufficiently fast temporal changes, the spatial changes of the potential above the station may become less pronounced, being stronger exposed to the temporal variations in the potential distribution patterns.

Unfortunately, the $E_{z}$ and $J_{z}$ recordings, notably in polar regions, are rather scarce and delayed in providing reliable atmospheric electricity data needed for research in other disciplines (Michnowski et al. 1991; Tinsley and Heelis 1993). The ionospheric electric fields are easier to be measured in situ over large areas by means of satellite and radar methods than by standard $E_{z}$ and $J_{z}$ ground-based recordings carried out until now. Due to the recent progress and activity in ionospheric observation techniques, a vast amount of systematically recorded data of the magnetospheric and ionospheric potential and fields in relation to solar wind parameters has been obtained. The data allowed to create statistical models of the ionospheric potential in relation to the IMF orientation and amplitude (e.g., Heppner 1977; Papitashvili et al. 1994; Weimer 1996, and references therein). Ground-based radar networks allowed to develop empirical models of the ionospheric potential (Ruohoniemi and Baker 1998). The empirical and semi-empirical models, extended by theoretical MHD and analytical models with the use of magnetometer data conversion, have allowed to estimate the potential not only over ground stations but also over the whole polar cap and auroral areas. The model potential distributions, broadly applied as input in computer simulations, have assisted in further investigations into the total $\mathrm{M}-\mathrm{I}$ response to solar wind changes. Continuous increase of the knowledge on physical links in SW-M-I couplings seems also to offer some new facilities for the exploration of the $E_{z}$ and $J_{z}$ response at ground level to the solar wind changes observed in the interplanetary space-we will discuss them in the final sections of the paper.

Sections 2-3 are reviews of a number of individual events observed during fair-weather conditions at Polish Polar Station Hornsund, Spitsbergen, and the middle latitude observatory Swider. Atmospheric electricity and solar wind data are presented on the background of meteorological, geomagnetic as well as other supplementary measurements outlined in Sect. 1. In the procedure, for the identification of such cases, average variations during steady M-I plasma convection at quiet magnetic conditions have often been used as a reference. But it is well known that the influences on the electric fields near the Earth's surface are exerted in various time and space scales and shaped by meteorological processes driven by huge electromagnetic heat energy delivered from the Sun rotating in 27-day cycle and undergoing activity changes at a timescale of $\sim 11$ years. The amount of energy, depending 

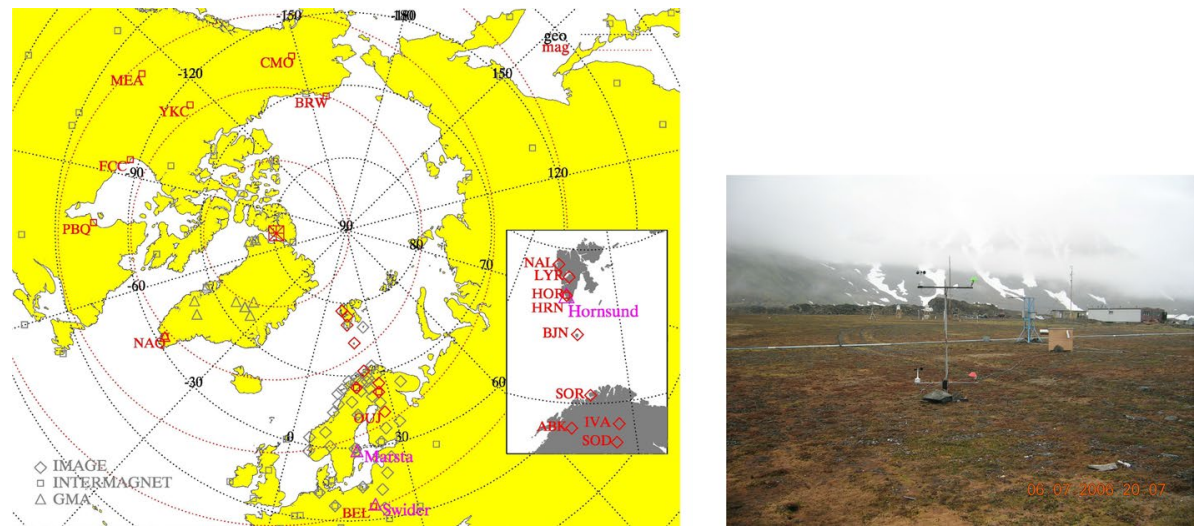

Fig. 2 Location of Polish Polar Station location in the south-west part of Spitsbergen: $\phi=77^{\circ} \mathrm{N}, \lambda=15.5^{\circ}$ $\mathrm{E}$; in corrected Geocentric Solar Magnetospheric (GSM) coordinates $\Phi=74.1^{\circ} \mathrm{N}, \Lambda=112.4^{\circ} \mathrm{E}$, and a map of Arctic magnetic stations from various magnetometer networks (see text). Hornsund (HOR) station belongs to the IMAGE magnetic network displayed over polar and Scandinavian regions, as well as to INTERMAGNET network as HRN. Swider Geophysical Observatory (SWI) is situated at middle latitudes in central Europe (Poland): $\phi=52.12^{\circ} \mathrm{N}, \lambda=21.23^{\circ} \mathrm{E}$; and $\Phi=47.8^{\circ} \mathrm{N}, \Lambda=96.8^{\circ} \mathrm{E}$. Photo: view of the station with electric field sensor on the right, credit: Archives of Geophysical Observatory in Swider, Institute of Geophysics PAS

on the Earth's surface position against the Sun, is changing with the Earth's rotation daily cycle around its own axis and orbiting around the Sun in yearly cycle. In consequence, the recorded $E_{z}$ (and $J_{z}$ ) variations undergo diurnal and seasonal changes. These and additional local effects in the diurnal variations will be illustrated in Sect. 4.

\section{Hornsund and Swider Station Recordings and Supplementary Data Sources}

The Polish Polar Station Hornsund $\left(\phi=77^{\circ} \mathrm{N}, \lambda=15.5^{\circ} \mathrm{E} ; \Phi=74.1^{\circ} \mathrm{N}, \Lambda=112.4^{\circ} \mathrm{E}\right)$ is located in the Hornsund fiord in the south-west part of the Spitsbergen island in the Svalbard archipelago. Depending on SW-M-I coupling and its intensity measured by geomagnetic activity, the station can be projected to regions either under the polar side of the auroral oval, directly under the oval, or quite often under the open geomagnetic field lines in the polar cap region (Michnowski and Nikiforova 1996; Kleimenova et al. 2010). The diversity of these situations extends possibilities of observing, at a given place at the ground level, various responses of the magnetospheric and ionospheric electric field and current system to solar wind changes at different helio-geophysical situations (e.g., Clauer and Banks 1986; Milan 2015), and thus to study the possible effects of the observed SW-M-I coupling in the electrical parameters of the Earth's lower atmosphere. The Hornsund station (Fig. 2) provides interesting observations of these effects, being the only site in the high Arctic where atmospheric electricity ground-level parameters are systematically recorded. The station work of this range has been continued since 1986; however, there were accidental gaps, some of which were caused by temporary lack of the needed equipment or its malfunction in polar conditions, as often happens especially with prototype instruments.

At Hornsund, the electric field measurements $\left(E_{z}\right)$ have been taken by a radioactive collector (Warzecha 1991) and simultaneously by a flat plate field mill (Chrobak et al. 1984) 
since 1989. The two sensors have been installed on high steel poles $(3 \mathrm{~m}$ for the field mill and $2 \mathrm{~m}$ for the radioactive collector), at a distance of $20 \mathrm{~m}$, in the flat area, approximately $180 \mathrm{~m}$ from the station buildings. The reduction of the field recordings to the flat ground surface level value has not been always strictly accomplished. The field mill errors are less than five percent, while the collector has distinct additional error (less than $15 \%$ ), part of which is affected by local meteorological conditions. In severe polar conditions, the field mill has kept its technical parameters accuracy of less than $6 \%$ at absolute calibration made four times yearly. Since 2005, improved field mill of rotating dipole type (Berlinski et al. 2007) has been used. Introduction of high-class electronic elements, special DC motor as well as the radio transmission of the dipole voltage signal without carbon brush commutator enabled to keep more stable work of the sensor. The signal indications were collected at $10 \mathrm{sec}$ resolution, converted to 1-min averages and on occasion to 1-h averages for the indication of mean hourly and diurnal variations. Sensor calibrations have been done once a year by placing a Faraday (shielded) box of dimensions $3 \mathrm{~m} \times 3 \mathrm{~m} \times 3 \mathrm{~m}$, containing parallel plates over the antenna, to which a stepped range of voltages was applied.

Recordings of vertical air-Earth current density at Hornsund $\left(J_{z}\right)$ have been carried in 1991-2004 by long wire antenna (Losakiewicz and Drzewiecki 1991). Although the $J_{z}$ parameter is considered in atmospheric electricity studies more representative than $E_{z}$ as being less dependent on local disturbances in the surface atmospheric layer, the profit of its application has been only partly delivered. During severe polar winters this long wire antenna had not been kept continuously in operation because of damages by polar bears and other technical problems.

In 1998, meteorological observations at Hornsund in the range of a synoptic station were replaced by automatic recordings performed by a Vaisala meteorological station. Each day, detailed local meteorological data and observers' notes have been used to select fair weather condition periods, i.e. free from atmospheric precipitation, fog, mist, hoar frost, wind with velocity higher than $6 \mathrm{~m} / \mathrm{s}$, blizzards and heavy overcast over the station (Imyanitov and Chubarina 1967; Kubicki 2002). At Hornsund only about $10 \%$ of full days satisfy such conditions. In addition, despite the rejection of the disturbed periods mentioned above, fair-weather intervals carefully chosen according the commonly accepted rules still appear to contain some local disturbances (Michnowski 1998; Kleimenova et al. 1998).

Other relevant geophysical recordings run concurrently at Hornsund included observations of the geomagnetic field run by Institute of Geophysics PAS (three components $X$, $Y, Z$ ), ionospheric absorption by a $30 \mathrm{MHz}$ riometer of the Space Research Centre PAS, indicating precipitation of energetic particles, and visual aurora observations within the scope of meteorological observations. The applied sampling of $10 \mathrm{~s}$ or $1 \mathrm{~s}$ in the electric and geomagnetic field components as well as in riometer measurements allows to reliably to record the phenomena with periods longer than $3 \mathrm{~min}$. Other supplementary data used in the analysis included magnetic records from International Monitoring of Aurora and Geomagnetic Effects-IMAGE ${ }^{1}$ network (e.g., Tanskanen 2009), INTERMAGNET ${ }^{2}$-International Real-time Magnetic Observatory Network (Rasson 2007; Love and Chulliat 2013), Greenland Magnetometer Array stations (Behlke 2016), and ionospheric convection maps from Super Dual Auroral Radar Network (SuperDARN) of ground-based HF back-scatter radars located at northern and southern high latitudes ${ }^{3}$ (Greenwald et al. 1995; Lester 2008,

\footnotetext{
1 Online at https://space.fmi.fi/image.

2 Online at https://www.intermagnet.org.

3 Online at http://vt.superdarn.org.
} 
2013). Solar wind data delivered by various satellite missions operating at the examined periods of interest were mainly gained from the NASA's Space Physics Data Facility's OMNIWeb database ${ }^{4}$ (Papitashvili et al. 2014) which combines solar wind and IMF measurements from satellite missions WIND (Ogilvie and Desch 1997) and ACE (Stone et al. 1998). Analysis of some cases has been supported by the use of OVATION auroral oval position model data ${ }^{5}$ (Newell et al. 1996, 2002; Sotirelis and Newell 2000).

The occurrence of middle-latitude atmospheric electricity response to SW-M-I coupling was revealed on the basis of the continuous registrations at S. Kalinowski Geophysical Observatory at Swider, Poland $\left(\phi=52.12^{\circ} \mathrm{N}, \lambda=21.23^{\circ} \mathrm{E} ; \Phi=47.8^{\circ} \mathrm{N}, \Lambda=96.8^{\circ} \mathrm{E}\right)$ carried on over more than recent 50 years (Warzecha 1991; Dziembowska 2009). Magnetic local noon corresponds there to $\sim 10$ UT. The instruments, their locations and data acquisition are described in more detail by Kubicki et al. (2007, 2016), and in the yearbooks of Swider atmospheric electricity data (e.g., Warzecha 1996; Kubicki 2002). A considerable number of supplementary atmospheric electricity parameters measured with various instruments (air electric conductivity of both polarities, cloud condensation nuclei (CCN) and aerosol concentrations, radioactive pollution, meteorological parameters etc.) recorded simultaneously at Swider allows to extend the evaluation of local effects disturbing the measured $E_{z}$ and $J_{z}$ beyond the abilities available at stations without such background longterm observations.

We also used an index of local magnetic activity, the K-index, evaluated using method of Nowozyński et al. (1991) on the basis of the geomagnetic field measurements: at Hornsund (IMAGE HOR station since 1993, INTERMAGNET HRN station since 2002) and at Belsk (BEL), the Main Geophysical Observatory of the Institute of Geophysics PAS, also an INTERMAGNET station (Reda and Neska 2016). Belsk Observatory is in the distance of about $50 \mathrm{~km}$ from Swider (SWI). The values of K-index have been obtained from magnetic observations yearbooks published regularly in Publications of the Institute of Geophysics, Polish Academy of Sciences (Glegolski and Gnoiński 2005, 2006; Marianiuk et al. 2005, 2007; Jankowski 2007; Reda et al. 2008, 2009, 2010; Neska et al. 2012a, b).

At the end of this section, we note that data from other atmospheric electricity polar stations might have been of value in our analyses. Unfortunately, the nearest available atmospheric electricity station Marsta in Sweden (Israelsson and Tammet 2001) at $\phi=59.93^{\circ} \mathrm{N}, \lambda=17.58^{\circ} \mathrm{E}$ (Fig. 2), could not be used as a source of reference data because usually no fair weather conditions were recorded simultaneously.

\section{Individual High Latitude Events of the $E_{z}$ and $J_{z}$ Responses to Solar Wind Changes}

Fair-weather $E_{z}$ and $J_{z}$ variations at high latitudes observed during solar wind induced M-I events are usually showing signatures of remarkable variety of shapes and magnitudes. Early polar atmospheric electric field recordings (Israël 1973; Lobodin and Paramonov 1972) made in fair-weather conditions during aurora and high magnetic activity had been bringing disparate and not consistent and repeating results. After year-long recordings in Alaska, Shaw and Hunsucker (1977) concluded that under similar circumstances there had

\footnotetext{
4 Online at http://omniweb.gsfc.nasa.gov.

5 Online at http://sd-www.jhuapl.edu/Aurora.
} 
been no response in $E_{z}$ at all. Later, when previously unattainable information on SW-M-I interactions was introduced to the analysis, the observations begun to reveal cases of some repeatable $E_{z}$ responses to these changes with a regular character. Findings from the Arctic, described in greater detail below, were extended by analysis of atmospheric electric recordings in the Antarctic, particularly at the South Pole and Vostok stations (Bering et al. 1988, 1991; Burns et al. 1995; Tinsley et al. 1998; Frank-Kamenetsky et al. 1999, 2001; Corney et al. 2003; Troshichev 2004; Lukianova et al. 2011; Victor et al. 2015). In particular, the Antarctic Plateau climate with predominant fair-weather periods made it possible to obtain quickly a large number of reliable $E_{z}$ data which were statistically analysed, and some statistically significant correlations between the chosen parameters have been found there in the last decades. Still, the existence of the searched physical dependence demanded direct confirmation in individual events. Usual comparisons of the magnetic and electric fields recorded at one site often appeared insufficient. More supplementary data on the M-I configuration changes driven by the solar wind have been required in order to see a more comprehensive picture of the phenomena involved. Examples of response to SW changes have been sought at rather extreme $E_{z}$ and $J_{z}$ disturbances. Despite rare occurrence of fair weather periods at Hornsund, the long-run recordings enabled us to select a substantial number of events likely to represent responses to solar wind-driven M-I disturbances.

Various kinds of reactions of the $E_{z}$ in different helio-geophysical circumstances such as during geomagnetic substorms, often observed at Hornsund in magnetic data, were expected to enlarge previous set of records from the Arctic. The dependence of site position against the auroral electrojet has been presented by recordings at Kola Peninsula and nearby auroral regions in the years 1976-1989 (e.g., Matveev et al. 1982; Bandilet et al. 1982a, b, c, 1985; Zhdanov et al. 1984, 1985; Afonina et al. 1985; Pumpyan et al. 1987). Out of several dozen previously examined cases of atmospheric electricity response to substorm with a clearly pronounced preliminary phase (Bandilet et al. 1986), a minority corresponded to the site position poleward of the polar electrojet. Such regularities were exemplified by other observations (Sheftel 1991; Anisimov et al. 1991; Kleimenova et al. 1992; Sheftel et al. 1994; Belova et al. 2000) as well as by several events recorded at Hornsund (Michnowski et al. 1991; Kleimenova et al. 1996; Nikiforova et al. 2003). Hornsund, situated much more often, sometimes very deep, in the polar cap region, compared to previously considered sites, delivered cases that enrich the statistics by adding new $E_{z}$ and $J_{z}$ response signatures.

\subsection{Quiet Magnetic Condition Cases}

In individual cases, some distinct deviations in $E_{z}$ or $J_{z}$ were noticed during carefully chosen periods of fair-weather conditions and at selected periods of almost steady values of geomagnetic field. One of such cases is shown in Fig. 3, an event recorded at Hornsund (HOR) on 23 April 1992. Between 18:15 UT to 20:15 UT, after a small negative magnetic bay before, at negative IMF $B_{y}$ values, the IMF $B_{z}$ showed reorientation from negative minimum to positive values of about $+1 \mathrm{nT}$, and subsequently went back towards the negative values. Similarly, the $E_{z}$ increased: the positive enhancement of this ground level parameter lasted for almost the same time as the positive enhancement of the $B_{z}$ values. The $E_{z}$ deviation amplitude reached values that were $20 \%$ larger than those estimated for an average departure from the mean daily value.

Afternoon positive enhancements of $E_{z}$ under the positive IMF $B_{z}$ were observed previously (Michnowski et al. 1991; Kleimenova et al. 1998). In this case, the $E_{z}$ deviation had 


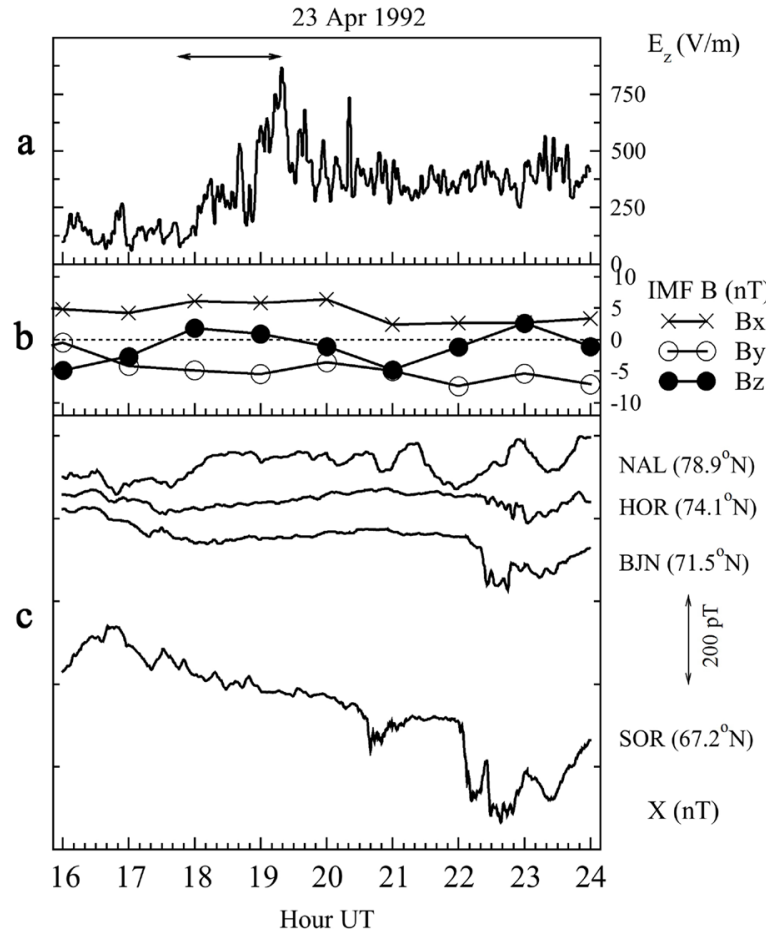

d

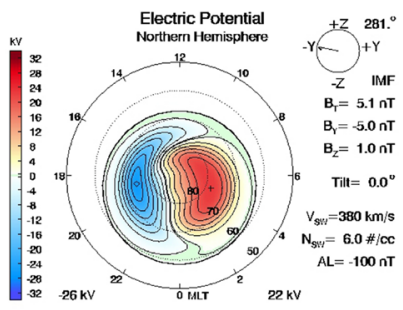

e

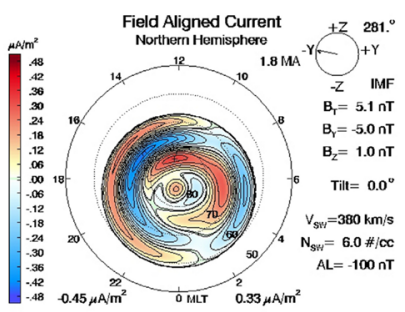

Fig. 3 An example of 23 April 1992, during fair weather conditions at 16-24 UT. Panels on the left: a time variations of electric field $E_{z}$ at Hornsund, b IMF components, and c geomagnetic field $X$ component at IMAGE stations NAL, HOR, BJN and SOR. Panels on the right: d ionospheric electric potential, e fieldaligned current distribution calculated from Weimer (2005a, b) model with IMF conditions at 19:00 UT as input parameters. The "quiet" period between 17:30 and 19:30 is marked in panel a) by horizontal arrow. Partly adapted from Michnowski et al. (2007)

an oscillatory character and took place in the absence of magnetic disturbances and geomagnetic pulsations when the recovery phase of the distant substorm in the south almost ended and the later magnetic disturbances have not started yet. $E_{z}$ and magnetic $X$ component signals filtered to $0.5-1.5 \mathrm{~Hz}$ show, despite their spectral coincidence, incoherent wave packets, indicating large oscillations in the $E_{z}$ signal at almost negligible fluctuations in the $X$ component. The ionospheric potential and FAC distributions, estimated on the basis of the Weimer model for the solar wind parameters of 19:00 UT, i.e. 22:10 MLT, demonstrate (Fig. 3d, e) that the station $\left(\Phi=77^{\circ}\right)$ at this time passed below the convection reversal and the R1 FAC on the polar side of the auroral oval. Probably Hornsund was then at the footprint of the FAC flowing from plasma sheet boundary layer which is often associated with enhanced aurora light. At Hornsund the aurora was not noticed at this time. Most probably this FAC was associated with large and time-steady spatial gradients seen in the ionospheric potential distribution.

Taking the above facts into account, it is reasonable to assume that the observed positive $E_{z}$ deviation may be related to the FAC directed downwards to the ionosphere. More sites of regional $E_{z}$ recordings are needed to recognise and to study such effects at ground level. 


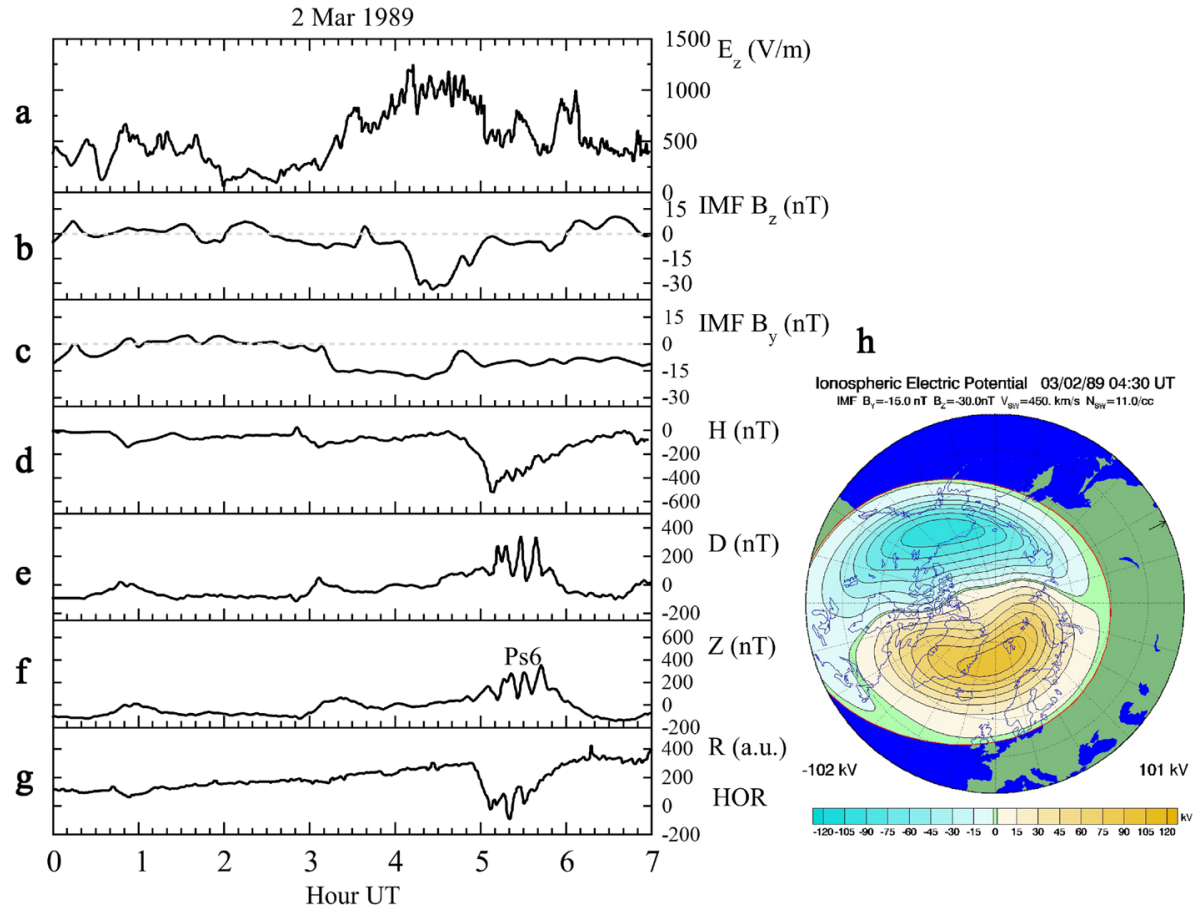

Fig. 4 Example of significant positive $E_{z}$ deviation at Hornsund during growth and expansion phase of the substorm recorded on 2 March 1989, 00-07 UT. Panels a-f on the left: time variations of the atmospheric electric field $E_{z}$ at Hornsund, IMF $B_{z}, B_{y}$, Hornsund geomagnetic $H, D, Z$ components and riometer absorption $R$. Plots reproduced from Michnowski et al. (1991, 1996). Very clear occurrence of magnetic pulsations of Ps6 type during the expansion phase of substorm (Kleimenova et al. 1992) is marked in panel f. Panel h-model ionospheric convection potential distribution at 04:30 UT, calculated with Weimer (2005a, b) model and IMF $B_{z}, B_{y}$, and OMNI solar wind plasma $N_{\mathrm{SW}}, V_{\mathrm{SW}}$ as input

\subsection{Cases of the $E_{z}$ and $J_{z}$ Responses to Magnetic Substorms at High Latitudes}

Magnetic substorms are episodic M-I perturbations with impulsive unloading of energy accumulated in the magnetospheric tail at periods of intense SW-M-I coupling (Sect. 1.1). They manifest themselves by energetic particle precipitation to polar atmosphere, intensification of plasma convection and field-aligned currents. The sporadically released energy from the magnetic tail, on average in the range of $10^{14} \mathrm{~J}$, is displayed in the inner magnetosphere, thermosphere, and ionosphere (Tanskanen et al. 2002; Pfaff 2012). As a result, the potential distribution and electric conductivity in and below the ionosphere affect the $E_{z}$ and $J_{z}$ values recorded at high latitudes near the ground surface. We now attempt to look into the various events at Hornsund with the use of extended range of additional data concerning various influences acting concurrently in local, regional and global scales.

Figure 4 demonstrates the distinct reaction in $E_{z}$ within a period of high magnetic disturbances with a series of magnetic substorms on 2 March 1989, the strongest one developing at $\sim 05$ UT (Michnowski et al. 1991; Kleimenova et al. 1992). This individual event was considered with the use of concurrent recordings of the magnetic $H$ and $D$ components and riometer data from Hornsund on the background of IMF $B_{z}$ and $B_{y}$ parameters. Previously known morphology of substorm $H, D$ magnetic perturbations allowed to state that 
this case represented a substorm occurring in early hours of 2 March 1989. Besides, the positive $Z$ component values roughly pointed out the station position at the south of the auroral electrojet centre according to an approximate location of the polar electrojet indicated between $71^{\circ}$ and $73^{\circ}$ of magnetic latitude by observations from the meridional chain of Greenland magnetometers (not shown). The growth phase of the substorm commenced after the southward turning of the north-south IMF component, $B_{z}$, and its negative values sustaining through a time (Fig. $4 \mathrm{a}-\mathrm{g}$ ).

In an attempt to explain such significant enhancement of the $E_{z}$, we calculated model values of the ionospheric convection potential over Hornsund from the Weimer statistical model (Weimer 2005a, b). Calculations based on hourly parameters of the IMF and plasma from OMNI database show an increase of the ionospheric convection potential over Hornsund, although not sufficiently large to explain the observed increase of $E_{z}$. In this time period, locally, the ionospheric potential appears to be higher than the model statistical values, allowing an increase of $E_{z}$ to the observed level. However, instant values of $B_{z}$ and $B_{y}$, as plotted in Fig. $4 \mathrm{~b}$, c, at 04:30 UT produced large, $\sim 200 \mathrm{kV}$ model values of the ionospheric potential, with Hornsund being at the time almost in the centre of the positive potential area. Such a situation seems to be possible in the case when Hornsund was located at the foot of the inflowing field-aligned current. There was still an uncertainty whether the examined enhancement is not of the local, lower-atmosphere origin, although in this case we exclude the most probable local effects such as local artificial pollution from the station that might sometimes cause a fast increase of the $E_{z}$ and keep it at relatively large values in fair weather. During substorms an increase in the amplitude of $E_{z}$ has been observed at the growth phase of the substorms, and the field decreased when a magnetic disturbance from the substorm was detected at the station-as has been usually observed in other cases (Olson 1971; Bandilet et al. 1986). This feature has been also observed at Hornsund (Kleimenova et al. 1992, 1996).

Another example of $E_{z}$ response to substorm events, observed on 27 October 2005, is presented in Fig. 5. The electric field variation is shown after averaging procedure (Kleimenova et al. 2010) in Fig. 5a. The first $E_{z}$ increase reached the peak value at about 00:40 UT at the growth phase of a substorm indicated by magnetograms from Hornsund (HOR) and other IMAGE meridian network of magnetic stations (NAL, ABK, IVA, SOD), plotted in Fig. 5b. The riometer absorption $R$ at lower-latitude stations ABK, IVA and SOD, is illustrated in the right bottom panel in Fig. 5c. The characteristic $E_{z}$ increase was continued in coincidence with the growth phase of the substorm at lower-latitude IMAGE stations (SOR, ABK, SOD) and even after the main phase began, as indicated by the large $X$ deflection at these stations. The highest $E_{z}$ peaks occurred during the enhancement of $R$ at ABK station. The systematic delays of peaks in $X$ component as the latitude decreases show the consecutive southward shift of the substorm position. In the right upper panel, in Fig. $5 \mathrm{~d}$, the position of Hornsund is shown in geographical coordinates on the background of OVATION data auroral oval for the time 00-01 UT. In Fig. 5e is its position on the background of a SuperDARN ionospheric electric potential distribution approximately at the time the highest and relatively short $E_{z}$ peak occurred. This position, found in the dawn cell, appears to lie near its convection boundary. It can be deduced that the auroral oval expanded southwards, leaving Hornsund in the polar cap.

Positive deviations in $E_{z}$ in the morning hours (01-04 UT, i.e. 04-07 MLT), such as that presented in Figs. 3 and 5, and in other Hornsund cases, have been explained as a result of the influence of morning substorms developing in the given side of the magnetosphere or of the fact that Hornsund was located in the area of the positive vortex of polar ionospheric convection; the first situation considered the main driver of such effects, according 
27. 10.2005

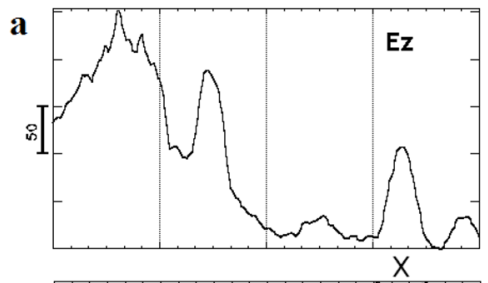

b

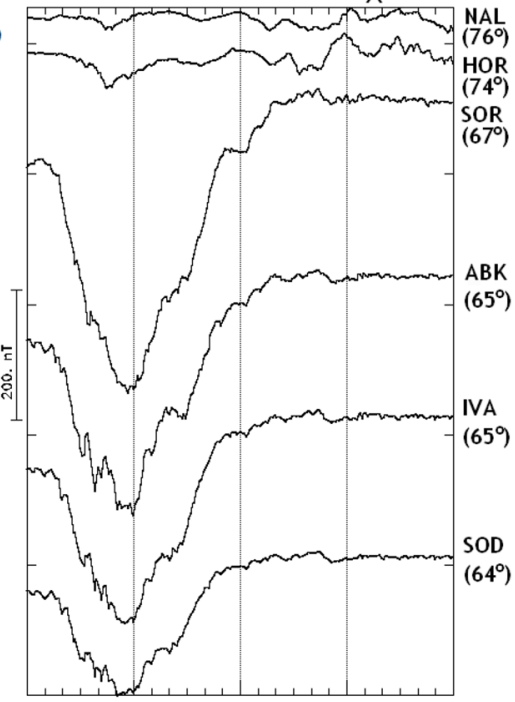

c

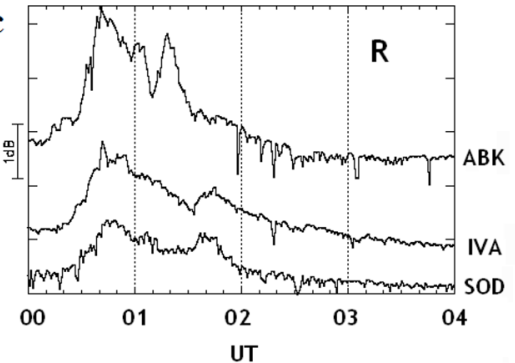

d

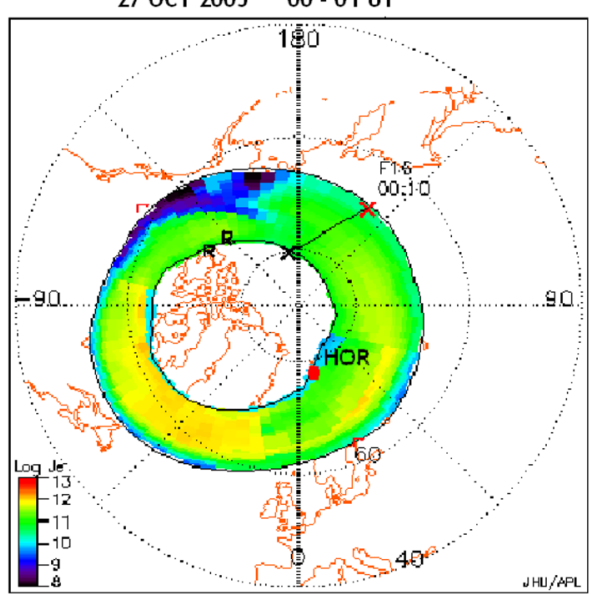

$\mathbf{e}$

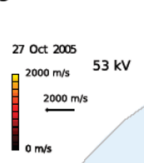

$00.30-00.32$ UT

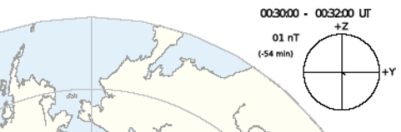

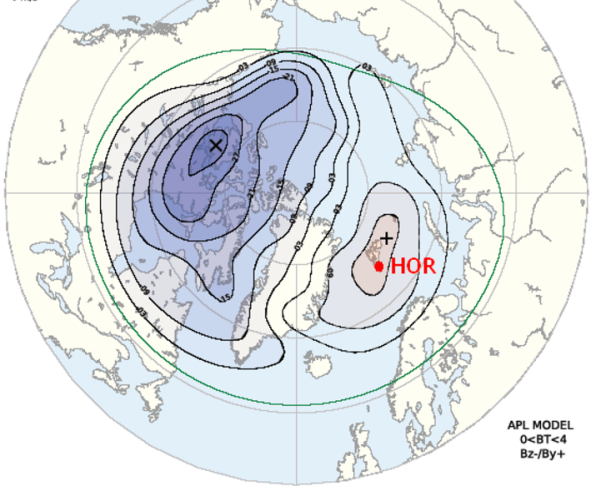

Fig. 5 Example of $E_{z}$ response to substorm at Hornsund on 27 October 2005: Left panels a variation of averaged measured $E_{z}$ in V/m, b magnetograms from IMAGE NAL, HOR, SOR, ABK, IVA and SOD stations, c concurrent riometer recordings $(R)$ at ABK, IVA, SOD stations. Panels on the right side: d OVATION map of the auroral oval in geographical coordinates at 00-01 UT, e SuperDARN ionospheric electric potential distribution map at 00:30-00:32 UT. The location of Hornsund is marked in red

to Kleimenova et al. (2011). Negative deviations in $E_{z}$ at evening and night-time hours 18-23 UT (21-02 MLT), or 11-16 UT (14-19 MLT), have also been observed, although it is more difficult to detect them. It was also noticed by Park (1976b) that the negative deviations at high latitudes had not been often reported by that time. Two such probable cases (22 and 23 of July 1998) have been investigated by Nikiforova et al. (2003). Earlier, Kleimenova et al. (1995) considered such situations, and in some these evening examples also positive deflections have been observed. These have been explained by decreasing size 


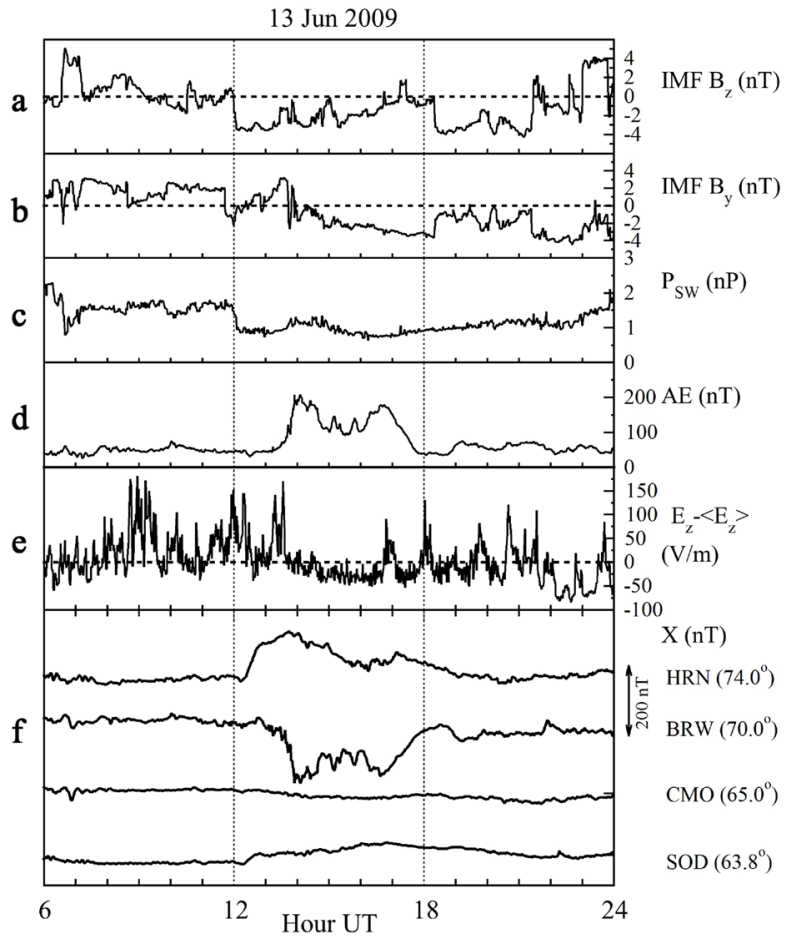

g

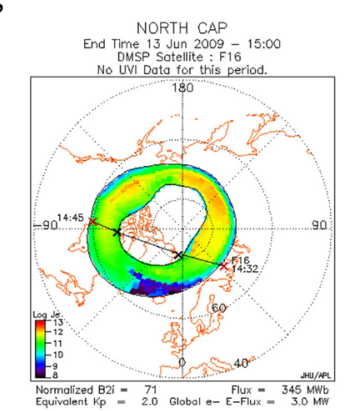

h

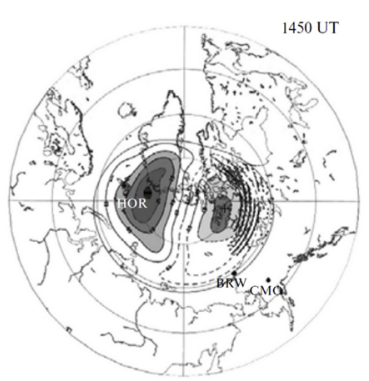

Fig. 6 Daytime variations of $E_{z}$ at Hornsund on 13 June 2009 and supplementary IMF, solar wind, ionospheric and magnetic data. Panels a-c IMF $B_{z}, B_{y}$ and solar wind pressure $P_{\mathrm{SW}}, \mathbf{d} \mathrm{AE}$ index, e deviation of $E_{z}$ from daily average value $\left\langle E_{z}\right\rangle$, f magnetic $X$ component data from INTERMAGNET stations HRN, BRW, CMO, SOD, $\mathbf{g}$ OVATION auroral oval model at 15 UT (black traces indicate path of DSMP satellites), h SuperDARN ionospheric convection potential distribution at 15:30 UT. Adapted from Kleimenova et al. (2012)

of the polar cap in accordance with the theoretical predictions of Volland (1972) and Park (1976a).

An opportunity to use SuperDARN and OVATION data products, in addition to solar wind and ground magnetometer data, appeared with investigation of more recent events. They provided additional information about the geophysical conditions during the events. Kleimenova et al. (2012) have analysed a number of cases which revealed daytime negative deviations of $E_{z}$ at Hornsund during locally quiet conditions and disturbed conditions in the night-time sector of the magnetosphere. A comparison of these variations with simultaneous values of the AE auroral activity index (Davis and Sugiura 1966) indicated that in the great majority of the considered cases, despite relatively quiet magnetic conditions at Hornsund $(\mathrm{K}=0-1)$, the negative deviations in $E_{z}$ at 11-18 UT were accompanied by an increase in AE up to 200-300 nT or more. At polar latitudes of the night-side magnetosphere, for example, at the Barrow station (BRW, $\Phi=70^{\circ}, \Lambda=250^{\circ}$ ), this period was characterised by substorms, which were absent at auroral latitudes at the College station (CMO, $\Phi=65^{\circ}, \Lambda=263^{\circ}$ ), and this was typical for weakly disturbed conditions. One of such examples on 13 June 2009 is shown in Fig. 6. After 12 UT, there occurred a period of mostly negative IMF $B_{z}$ and $B_{y}$ in the range from -4 to 4 pT (short positive excursions) and solar wind pressure below $2 \mathrm{nPa}$ (panels in Fig. 6a-c). The amplitude of the night polar 


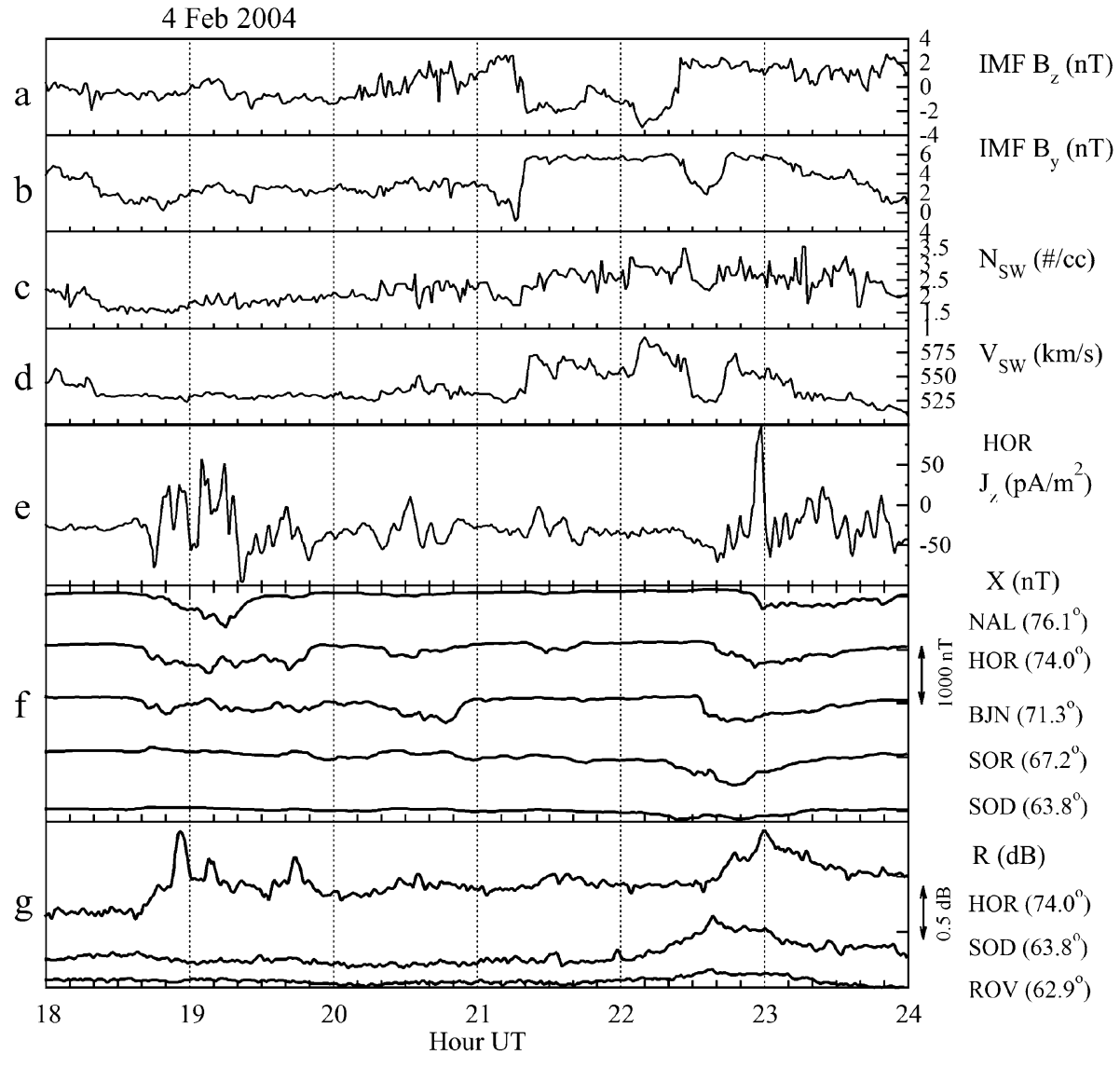

Fig. 7 Case of $J_{z}$ variations at Hornsund on 4 February 2004, 18-24 UT. Panels show: a-b IMF $B_{z}, B_{y}$ components, $\mathbf{c}-\mathbf{d}$ solar wind density $N_{\mathrm{SW}}$ and speed $V_{\mathrm{SW}}$, e electric current density $J_{z}$, f geomagnetic $X$ component, $\mathbf{g}$ riometer absorption $R$, observed at Hornsund and selected IMAGE stations. Adapted from Kozyreva et al. (2007)

substorm at BRW was around $200 \mathrm{nT}$, and it was not detected at auroral latitudes at CMO and SOD. At this time, the Hornsund observatory recorded an eastern electrojet (Fig. 6f). Variations of the AE index are plotted in Fig. 6d. The $E_{z}$, shown in Fig. 6e, between 13 UT and 16 UT remained at a steady level below its daily average value, after which a few positive deviations have been observed. Figure $6 \mathrm{~g}$, h shows an OVATION model of the auroral oval at 15 UT and a SuperDARN map global ionospheric convection at 15:30 UT. This coincides with the middle of the substorm period at BRW and indicates that the Hornsund observatory was located in the area of a negative convection vortex at 15:30 UT and inside the auroral oval at 15:00 UT (Kleimenova et al. 2012), and both may explain the suppression of $E_{z}$ at that time. OVATION displays from later hours (not shown) indicate that about 20 UT Hornsund was far away from the polar side of the auroral oval.

At the end of this subsection, we review a case of oscillations observed during magnetically disturbed period at Hornsund in the electric current density, $J_{z}$. They have been observed during fair weather conditions at substorm disturbances on 4 February 2004 
(Fig. 7). The oscillations occurred during main phases of two substorms recorded by the IMAGE network. The first one was observed on that day at HOR and NAL at 18:20 UT, while the other was seen in the zone of lower, auroral latitudes at 22:23 UT. Both of them quickly propagated into polar cap latitudes, as in the case of other similar substorm events reported, for example, by Stauning et al. (1995). Variations observed at the Earth's surface have about 40-min time lag against the solar wind parameter recordings carried on by ACE satellite in the front of the magnetosphere (Fig. 7a-d). With this delay, the two substorms followed a period of negative (southward) $B_{z}$ and short positive impulses of this IMF component from negative to positive values and back. During these substorms, the negative $B_{z}$ values were accompanied by a jump of $B_{y}$ component to large positive values that have sustained for about $1 \mathrm{~h}$, and a similar jump of solar wind velocity, $V_{\mathrm{SW}}$. Noteworthy is also the simultaneous and considerable increase of solar wind particle density, $N_{\mathrm{SW}}$. This means that the interplanetary electric field embedded with the IMF in the solar wind behaved in a similar way, and so does the solar wind dynamical pressure. In the behaviour of $V_{\mathrm{SW}}, N_{\mathrm{SW}}$ one may notice fluctuations, especially in the solar wind particle density. During both substorms, the $J_{z}$ variations demonstrated large impulsive long-period pulsations (Fig. 7e). They were associated by an enhancement of absorption $R(<1 \mathrm{~dB})$ with fluctuations and simultaneously by long-period (1-10 min) geomagnetic field pulsations, as shown in Fig. 7f, g. Simultaneous occurrence of these variations was tested by wavelet analysis (Kozyreva et al. 2007). The frequency distribution structure of the examined variations appeared to be similar, also in small separated bursts of these variables noticed at Hornsund between 20 and 22 UT. It has been suggested that the character of the geomagnetic field, electric current and energetic electron precipitation quasi-periodic variations implied the driving role of energetic particle flux in this case.

The deviations of $J_{z}$ were observed, with about half an hour delay, after the previously described changes in the solar wind parameters and IMF intensity and orientation. The geomagnetic field component $X$ recorded at IMAGE stations shows a bit earlier reaction (Fig. 7f). Noteworthy is the considerable correspondence between solar and ground electric parameter courses, their abrupt increase to almost steady high values persisting for almost $1 \mathrm{~h}$ and decaying rapidly. Belova et al. (2000) have been observing at Kiruna, Sweden, statistically, an increase of $J_{z}$ intensity $2 \mathrm{~h}$ prior to magnetic $X$ component minimum. They also showed that statistically $J_{z}$ and its fluctuations increase during substorms. The latter seems to be a more commonly observed $J_{z}$ reaction, also reported by Yair et al. (2013), Elhalal et al. (2014) at the low latitude of Mitzpe-Ramon, Israel, during magnetic storms.

\section{Individual Cases of Ground-Level $E_{z}$ and $J_{z}$ Response to Magnetic Storms}

During a coronal mass ejection (CME), the erupted solar plasma cloud with the imbedded IMF can have impact on the Earth's magnetosphere when the ejection is launched close enough to the Sun-Earth line, causing a long-lasting M-I disturbance called a magnetic storm (Gonzalez et al. 1994). The produced severe geomagnetic field departures from normal behaviour lasting usually from one to several days are observed at middle and low latitudes in the characteristic reduction of the magnetic component $H$. Average magnetic $H$ deviation patterns reported by low-latitude stations allow to establish the $D_{\text {st }}$ index that is used to indicate the intensity and duration of the storms (Loewe and Prolss 1997). At high latitudes, the magnetic storm appears usually as a series of subsequent substorms. 


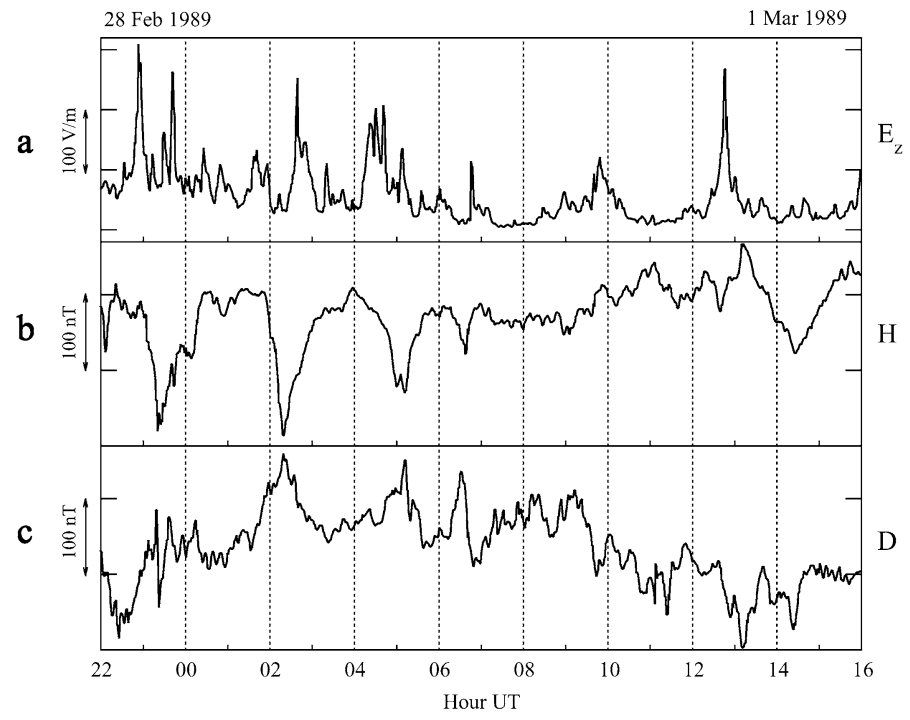

Fig. 8 Variations of atmospheric electric field $E_{z}$ (a), and geomagnetic field components $H$ and $D(\mathbf{b}-\mathbf{c})$ at Hornsund from 22:00 UT, 28 February 1989, to 16 UT on 1 March 1989, during prolonged magnetic disturbances

\subsection{Cases of $E_{z}$ and $J_{z}$ Response at High Latitudes to Magnetic Storms}

A series of substorm polar disturbances in geomagnetic components $H$ and $D$, observed from 28 February to 1 March 1989, at Hornsund, and the corresponding response of the electric field is shown in Fig. 8. The variation of $E_{z}$, measured by a field mill, was compared with simultaneous recordings by a radioactive collector, and the records by the two independent instruments had a good correlation (Michnowski et al. 1991). For the interval shown in Fig. 8a, the correlation coefficient between the series was 0.82 .

This case cannot be qualified formally as a magnetic storm, since here the minimum value of the $D_{\text {st }}$ index is a bit less than the conventional threshold of $-30 \mathrm{nT}$. Nevertheless, the morphological features of the recorded geomagnetic field $H$ and $D$ components, shown in Fig. 8b, c, indicate subsequently occurring disturbances which be treated as typical for substorms in polar regions associated with a magnetic storm. In the time interval under study, Hornsund was situated within the polar cap $(\mathrm{Kp}>4)$ and the increases of $E_{z}$ in the morning hours during the substorm growth phases was consistent with a regularity noticed previously, especially for morning sectors.

\subsection{Sudden Storm Commencement Effects on High-Latitude $E_{z}$ and $J_{z}$ Variations}

An example of $E_{z}$ and $J_{z}$ response to sudden storm commencement (SSC) (Akasofu and Chapman 1959; Araki 1994) after a powerful coronal mass ejection on the Sun is illustrated in Fig. 9. This event occurred after the first impact of the CME on the Earth's magnetosphere on 15 July 2000 at about 14:38 UT, which resulted in a magnetic storm. The $D_{\text {st }}$ index which plotted in the upper panel, in Fig. 9a, reached the peak value of -300 nT. The rapid magnetic activity enhancement of this storm was recorded at IMAGE 


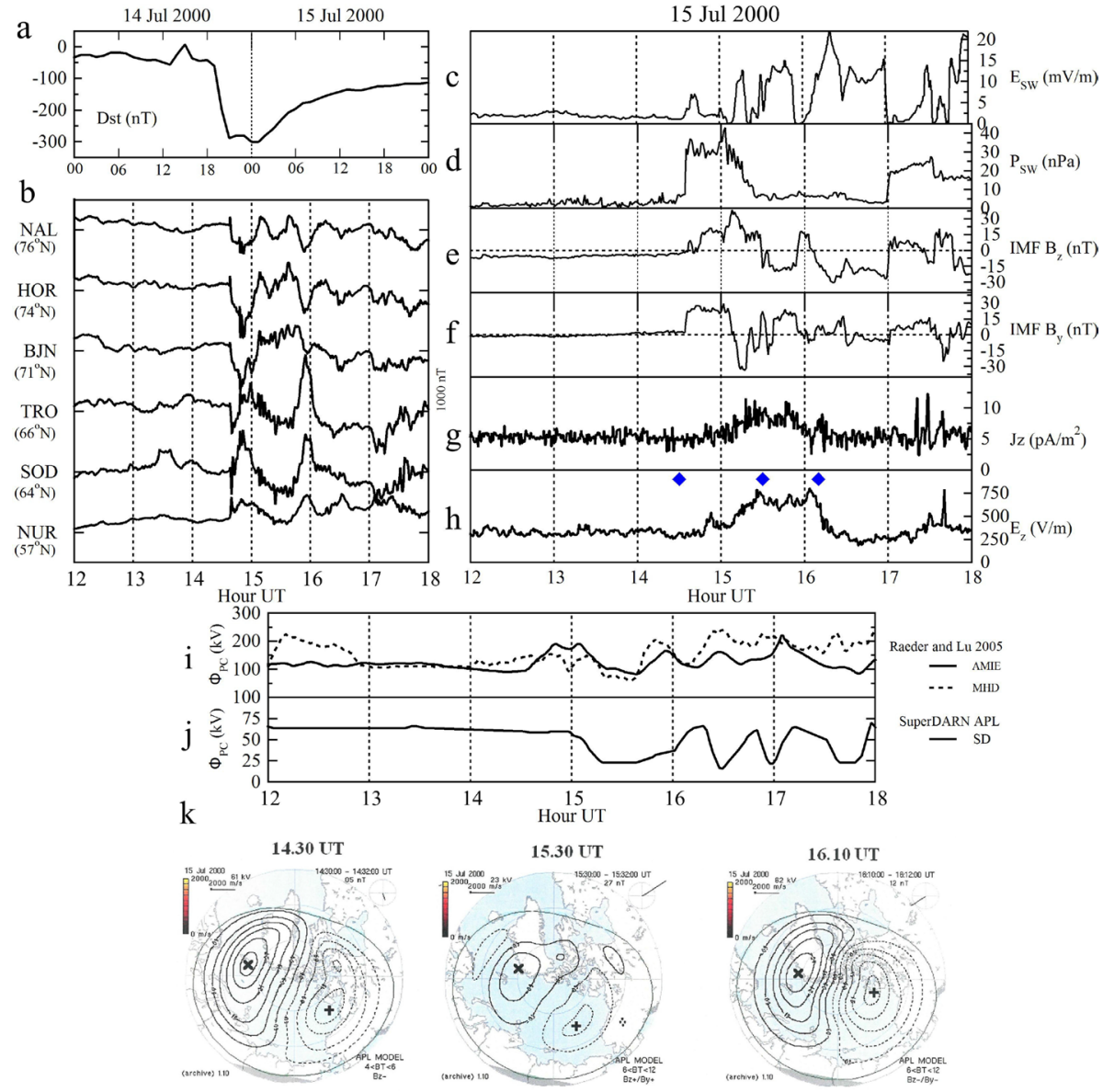

Fig. 9 Variations of the $E_{z}$ and $J_{z}$ at Hornsund during the initial phase of the magnetic storm on 15 July 2000, 12-18 UT. Upper panels on the right: a $D_{\text {st }}$ index variations on 14-15 July 2000, b geomagnetic $X$ components at IMAGE stations. Upper panels on the left: $\mathbf{c}-\mathbf{f}$ time variations of solar wind and IMF parameters measured by satellites in front of the magnetosphere (OMNI data), $\mathbf{g}-\mathbf{h}$ variations the $E_{z}$ and $J_{z}$ at Hornsund. Bottom panels: $\mathbf{i}-\mathbf{j}$ time variations of cross-polar cap electric potential by an MHD model and the AMIE procedure as in Raeder and Lu (2005), and from the APL model based on SuperDARN data. Bottom panel k: APL SuperDARN ionospheric convection potential distributions at 14:30 UT, 15:30 UT and 16:10 UT (moments marked by diamonds in panel $\mathbf{h}$ ). The contours are the equipotential lines, where the solid lines represent positive potential, while dashed lines-negative potential. The sign " $x$ " and "+" locate the position of minimum and maximum of the potential. Electric potential data reproduced from Raeder and Lu (2005) and archived materials (Kleimenova et al. 2008b)

stations-variations of the $X$ components are shown in Fig. 9b. It happened almost simultaneously with very strong abrupt jumps in solar wind parameters (Fig. 9c-f), especially large in the dynamic pressure, $P_{\mathrm{SW}}$, recorded at the front of the bow shock by GEOTAIL satellite about half an hour earlier (due to the corresponding time of signal passage from the satellite location to the Earth). The solar wind dynamic ram pressure jumped suddenly up to $+32 \mathrm{nPa}$, sustained the high level for about $1 \mathrm{~h}$, and subsequently dropped down. This time, the $B_{z}$ component of the IMF increased abruptly from low negative to very high 
positive values, with maximum of $+30 \mathrm{nT}$, and decayed later to large negative values which returned to the values preceding the $E_{z}$ enhancement. On the other hand, the IMF $B_{y}$ component, after simultaneous jump to considerably large positive values, fell down to negative values and returned back to the previous high positive values with oscillations. Simultaneously with these changes, the solar wind speed, $V_{\mathrm{SW}}$ (not shown) jumped from 300 to about $700 \mathrm{~km} / \mathrm{s}$, keeping continuously a high value for more than two and half hours before its next jump to $900 \mathrm{~km} / \mathrm{s}$. Due to the behaviour of $V_{\mathrm{SW}}$ and $B_{z}$, there was also a jump of the solar wind interplanetary electric field $\left(E_{\mathrm{SW}}=V_{\mathrm{SW}} \times B_{z}\right)$ in the shape more similar to $B_{z}$ variations due to almost constant $V_{\mathrm{SW}}$ values in the considered time of $E_{z}$ enhancement caused by the SSC. The shape of the $E_{\mathrm{SW}}$ pulse was not so explicit as that one of the dynamical ram solar wind pressure, $P_{\mathrm{SW}}$, which both sustained together for about 1 h.

The $E_{z}$ and $J_{z}$ values recorded at the Earth's surface (Fig. 9g, h) responded to the sudden jump of solar wind parameters by a considerable increase followed by an abrupt decrease. This jump occurred about 20 min later than the immediate sharp magnetic activity response which sustained for a time and rapidly decayed. The amplitudes of this enhancement reached the values nearly three times larger than the average value persisting during at least two and a half hours before. This large level is more than two times higher in reference to an average $E_{z}$ and $J_{z}$ departure from the mean value for the corresponding period on relatively quiet magnetically summer days. The features of the $E_{z}$ and $J_{z}$ response to the SSC may differ. During the SC caused by the bow shock with a very similar jump of $P_{\mathrm{SW}}$ but accompanied by negative $B_{z}$, the enhancements of $E_{z}$ and $J_{z}$ have not been observed.

The bottom panels, in Fig. 9i, j, show cross-polar cap potential difference, $\Phi_{\mathrm{PC}}$, determined from an MHD model calculations and by experimental data obtained by means of assimilative procedure AMIE - both from Raeder and Lu (2005), and from the APL model based on SuperDARN observational data. The occurrence of the first sustained jump of $\Phi_{\mathrm{PC}}$ values determined by AMIE does correspond to jump of $P_{\mathrm{SW}}$ and of other solar parameters, while the $\Phi_{\mathrm{PC}}$ course simulated by the MHD model is distinctly not consistent in this period of time. Also the AMIE jump is not in accordance with the APL model values obtained from SuperDARN data, shown in panel of Fig. 9j. Bottom panel, Fig. 9k, shows the ionospheric electric potential distribution patterns from SuperDARN, pertaining to the situations before, during, and after the $E_{z}$ enhancement. The visual inspection of the SuperDARN maps allows to ascertain that Hornsund at 15:30 UT, during the time of enhancement, was situated close to a small positive convection cell within the dusk sector dominated by negative circulation and negative potentials. This situation coincides with positive orientation of IMF at the time of large $B_{z}$ values, at which a lobe reconnection occurs at the Northern Hemisphere. The enhancement occurred in the dusk sector at the considerable decrease of $\Phi_{\mathrm{PC}}$, while one should rather expect a decrease of the ionosphere potential there. However, at the hourly exposition of the large positive $B_{z}$ values there occur positive enhancements of the ionosphere potential due to NBZ field-aligned currents, and it is such an enhancement that is demonstrated by SuperDARN estimation. Alas, the indicated positive enhancement in the form of a small bay is localised at a considerable distance from the position of Hornsund during corresponding MLT. For elucidation of this singular case, more detailed data would be necessary. However, the effects of the NBZ current system in the form of daytime $E_{z}$ enhancements at Hornsund have been more recently investigated in other several cases by Kleimenova et al. (2017). 


\subsection{Cases of Response of $E_{z}$ and $J_{z}$ Variations at Mid-Latitudes to Magnetic Storms}

Potential individual effects of magnetic storm on $E_{z}$ or $J_{z}$ variations have been reported for cases observed at high and middle, and even low latitudes, as mentioned earlier. Search for a reaction at middle latitudes made for Swider station on the basis of 15-year statistics resulted in detecting correlations between the $E_{z}$ and magnetic activity index Kp index (Bartels et al. 1939) but only in daily, yearly and long time spans (Kalinowska-Widomska 1977; Nikiforova and Michnowski 1977). Statistical correlations in the range of seasonal and long term behaviour of solar and atmospheric electric relations have been researched by others authors (Sao 1967; Rao 1970). In individual events, this dependence was not found. A case of such an event was for the first time perceived at Swider during the main phase of the magnetic storm on 30 October 2003 (Nikiforova et al. 2005). Effects of this storm appeared in the $X$ geomagnetic field component simultaneously over wide latitude range of IMAGE magnetometer stations (TAR, NUJ, NUR) and at lower-latitude station Belsk (BEL) during local midnight hours. As we re-examine the case, we concluded that the field reaction observed at Swider including a negative deflection, concurrent with time changes in $X$ component and absorption $R$ at JYV station, had similar frequency structure as was demonstrated by wavelet analysis; however, they also have been partly affected by meteorological factors, since the fair-weather conditions were not strictly fulfilled throughout the whole period. Nevertheless, further investigations by Kleimenova et al. (2008a, 2013), made on the basis of Hornsund and Swider data, and 30 cases of magnetic storms over 2000-2004, revealed several repeatable responses of the $E_{z}$ at Swider during magnetic storm conditions. For the illustration of such events, some examined cases are shown below.

Figure 10 presents a case of negative deviations in the $E_{z}$ at Swider during the storm on 13-14 October 2000, when the $D_{\text {st }}$ index, as shown in the top panel, in Fig. 10a, points out two minima, i.e. a two-step development (Kamide et al. 1998) of the moderate magnetic storm, and indicating ring current enhancements: the first one, which occurred at 01-08 UT of 13 October, and the second, at $05-18$ UT on the next day. Solar wind and IMF parameters are shown in panels in Fig. $10 \mathrm{~b}-\mathrm{e}$. During both $D_{\mathrm{st}}$ minima, the IMF $B_{z}$ had southward orientation. At Swider, the $E_{z}$ demonstrated deviations from magnetically quiet average diurnal $E_{z q}$ variation of one of previous fair-weather days (panels in Fig. 10f, g). At the time of these anomalous $E_{z}$ changes, no magnetic disturbances had been observed at nearby magnetic station Belsk (BEL, $\Phi=47.3^{\circ} \mathrm{N}, \Lambda=96^{\circ} \mathrm{E}$ ). The changes in $X$ geomagnetic component recorded at $\mathrm{CMO}$ station $\left(\Phi=64.7^{\circ} N ; \Lambda=203^{\circ}\right)$, as well as at (SOD) Sodankyla $\left(\Phi=63.8^{\circ} \mathrm{N}, \Lambda=108^{\circ} \mathrm{E}\right)$ are presented in the bottom panel, in Fig. 10h. It is noteworthy that the recorded deviations in $E_{z}$ at Swider took place during daytime when a magnetic substorm occurred at CMO station at the night side, and at the SOD station, both placed in the auroral oval. The CMO station is placed opposite to Swider in the Earth's hemisphere so that the magnetic local noon at Swider ( $\sim 10 \mathrm{UT})$ approximately corresponds to the magnetic local midnight at CMO. The differences between the observed $E_{z}$ and the average values of $E_{z q}$ at magnetically quiet conditions, $E_{z}-E_{z q}$, indicate deflections shown in the middle panel panels in Fig. 10g. In the first hours of October 13, a deep depression of this difference occurred at high negative values of IMF $B_{z}$ (with a short positive excursion) associated with high positive values of solar wind interplanetary electric field $E_{\mathrm{SW}}$ (also with a short excursion) and during high values of long-sustained jump of solar wind dynamical pressure, $P_{\mathrm{SW}}$. This negative deviation of $E_{z}$ was followed by an enhancement of $B_{z}$ to high positive values (nearly $+20 \mathrm{nT}$ ) during still sustaining jump of 


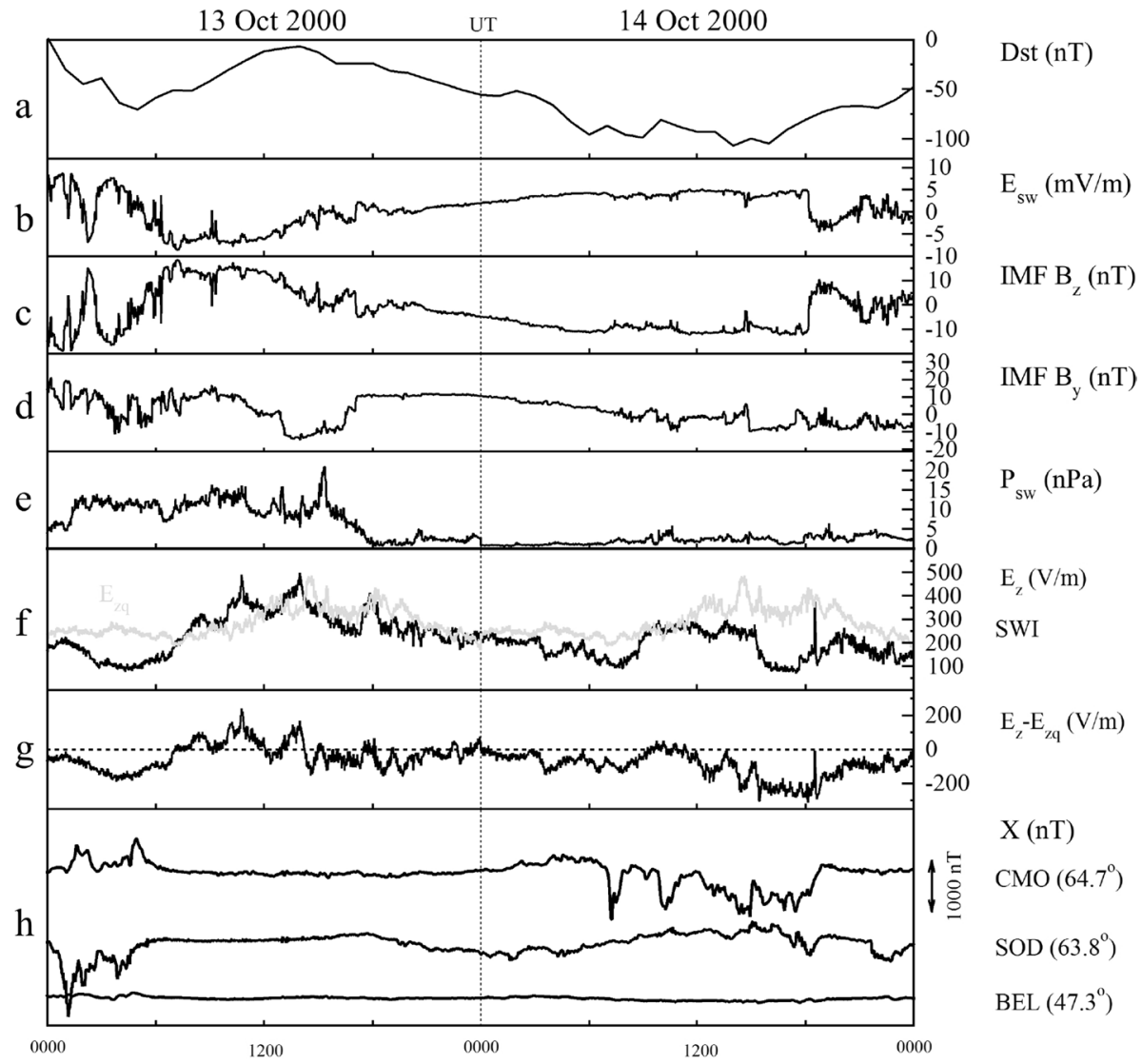

Fig. 10 The response of $E_{z}$ at mid-latitude Swider station to the magnetic storm of 13-14 October 2000. Upper panels a-e show $D$ st-index and variation in solar wind parameters: pressure- $P_{S W}$, interplanetary electric field- $E_{S W}$ and IMF components $B_{z}, B_{y}$. Middle panels $\mathbf{f}-\mathbf{g}$ show the fair-weather $E_{z}$ during the event and $E_{z q}$ at a quiet time on previous fair weather magnetically quiet day, and the difference $E_{z}-E_{z q}$ between the disturbed and quiet values. Bottom panel h shows magnetic variations in the $X$ component at CMO, SOD, and BEL station. See also Kleimenova et al. (2008a), Fig. 2a-b

$P_{\mathrm{SW}}$ and during a large decrease of $E_{\mathrm{SW}}$ and resulted in a positive deviation of $\left(E_{z}-E_{z q}\right)$. On the next day, this deviation changed the sign, indicating a large depression of the measured $E_{z}$ which is not usual during fair weather. This event was associated with large solar wind electric field $E_{\mathrm{SW}}$ and negative $B_{z}$. Next large negative $\left(E_{z}-E_{z q}\right)$ was accompanied by a decrease of $B_{y}$ to negative values during high positive $E_{\mathrm{SW}}$ and high negative $B_{z}$ values.

Another example of a magnetic storm effect on $E_{z}$ variation, observed at Swider on 23-24 May 2000, is illustrated in Fig. 11. The reaction of $E_{z}$ was recognised on the background of average fair-weather quiet magnetic $E_{z q}$ variations in the previous day. The first deflection $\left(E_{z}-E_{z q}\right)$ indicated in panel of Fig. $11 \mathrm{~g}$ by positive enhancements in early morning hours was associated with a jump of dynamic pressure $P_{\mathrm{SW}}$ and high values of solar wind electric field $E_{\mathrm{SW}}$, shown among $D_{\mathrm{st}}$ index and other IMF and solar wind parameters in Fig. 11a-e. The second afternoon deflection in the shape of considerable depression of the recorded $E_{z}$ corresponded to the strong $X$ disturbances which occurred at auroral station (CMO and SOD) in both hemispheres, as presented in Fig. 11h. 


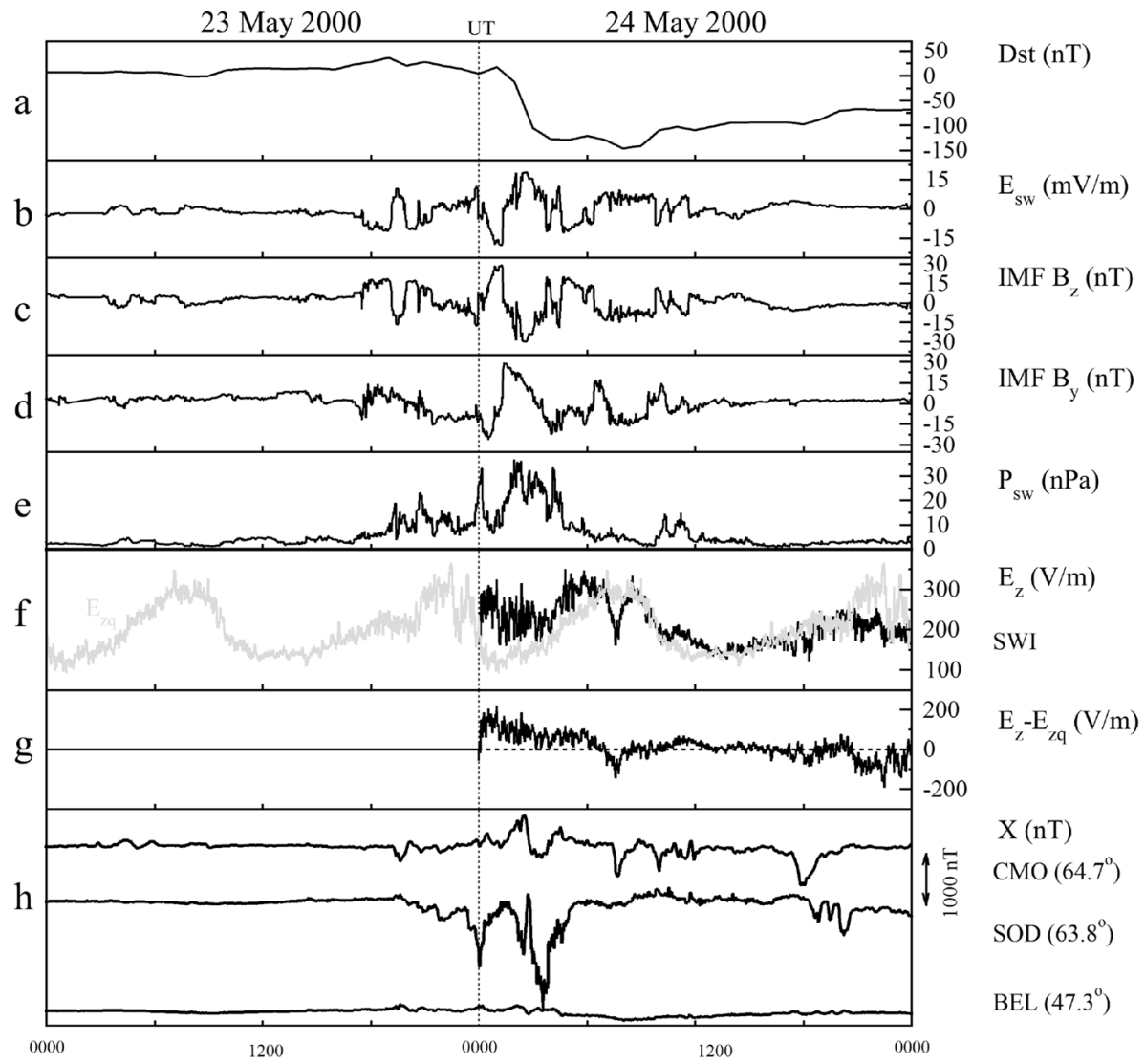

Fig. 11 The response of $E_{z}$ at mid-latitude Swider station to the magnetic storm of 23-24 May 2000. Description of panels the same as in Fig. 10. See also Kleimenova et al. (2008a), Fig. 3a-b

The feature of negative (i.e. below reference value) deviations of $E_{z}$ during the main phase of the magnetic storm and simultaneous with magnetic activity at CMO station has been observed in other cases (Kleimenova et al. 2008a, 2013). Kleimenova et al. (2009) have analysed the behaviour of the $E_{z}$ in the days following a magnetic storm interpreted as a result of a Forbush effect of cosmic rays. Cosmic rays are the main factor responsible for a partial ionisation of the lowest atmospheric layers and observed modifications of cosmic rays associated with magnetic storms, including Forbush effects, should reduce the atmospheric conductivity and further to affect the global electric circuit. Effects of the reduction of atmospheric electric field during such events have been perceptible at high- and midlatitude atmospheric electricity stations (e.g., Sheftel et al. 1992; Märcz 1997). At a land station like Swider, a field increase or decrease could be also associated with a change in the aerosol type and concentration. It is therefore advisable to monitor the remaining basic atmospheric parameters such as conductivity or electric current density.

In Fig. 12, we review yet another example of a considerable decrease of atmospheric electricity parameters during a magnetic storm on 3 October 2001. Compared with previously analysed cases, a decrease of the electric field $E_{z}$, and current density $J_{z}$, has been observed in this case (Michnowski et al. 2014), as well as a decrease of conductivity (not 


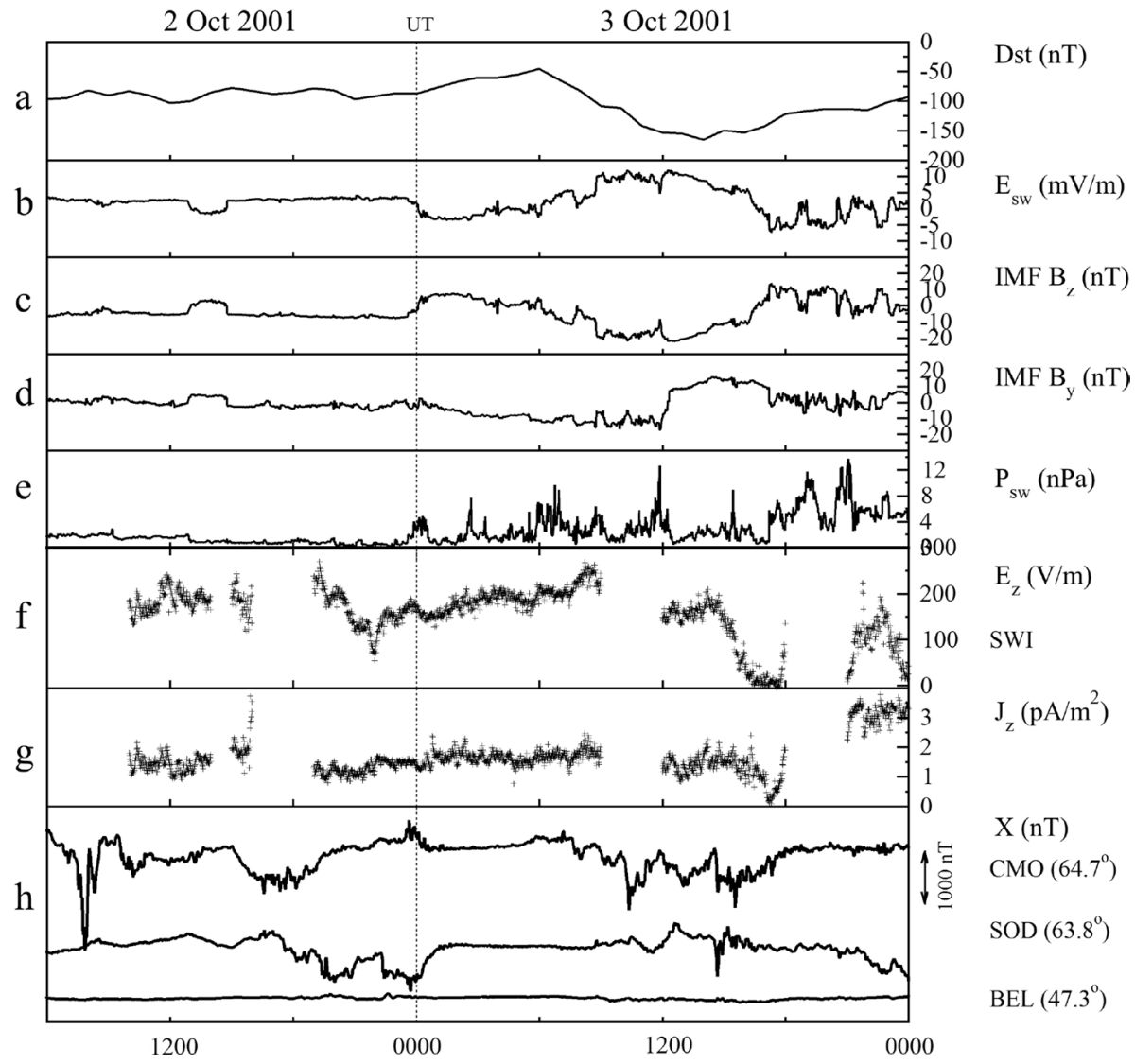

Fig. 12 The response of $E_{z}$ and $J_{z}$ at mid-latitude Swider station to the magnetic storm of 3 October 2001. Panels show: a-e variations of $D_{\text {st }}$ and solar wind parameters, $\mathbf{f}-\mathbf{g}$ atmospheric electricity parameters (only fair-weather values are shown), $\mathbf{h}$ variations of magnetic $X$ component at BEL, SOD and CMO INTERMAGNET stations

shown). Top panels in Fig. 12a-e show the variation of $D_{\text {st }}$ index indicating a magnetic storm, and simultaneous parameters of the IMF and solar wind. A higher magnetic activity was present at both SOD and CMO stations, as shown in the magnetograms displayed in the bottom panel, in Fig. 12h. At the start, the magnetic activity has already been higher $(\mathrm{Kp}=5)$ and it continued to increase as the $D_{\text {st }}$ index reached the value of $-166 \mathrm{nT}$ at $\sim 14$ UT. The IMF $B_{z}$ became largely negative from about 6 UT (with three negative excursions of smaller amplitudes earlier) until 16 UT. The $B_{y}$ component changed its sign from negative to large positive amplitudes up to $+15 \mathrm{nT}$ shortly after $12 \mathrm{UT}$ and remained at similar level until about 17 UT. There were also a few rapid increases in the solar wind pressure throughout the day, with the largest at about $12 \mathrm{UT}$.

Middle panels, in Fig. 12f, g, show the behaviour of the electric parameters. Empty spaces indicate periods of disturbed weather. Till 9 UT, $E_{z}$ and $J_{z}$ have been on a level comparable with previous day, 2 October 2001. Their amplitudes decreased slightly around 12 UT on 3 October 2001, and at 15 UT began to decrease dramatically, until shortly before 18 UT. The variations from 18 UT until at least 21 UT and early hours of the next day 
cannot be considered because fair-weather conditions were absent. The meteorological report from Swider at 18 UT indicates cloudiness level of 2/8, earlier 0/8 at 6 UT and 1/8 at 12 UT with Altostratus clouds present. Rainfall was detected later between 18:56 and 19:26 UT (Kubicki 2002). The change of the electric field could partly be caused by the cloud arrival or reduction of conductivity being caused by an increase of aerosol pollution, as often happens at Swider at this time of day and year. On that day CCN concentration increased from $\sim 12,000$ particles/cc at 6 UT and 12 UT to 22,000 particles at 18 UTthus, the decrease of the atmospheric electricity parameters can also be explained as being of atmospheric origin, although its amplitude was relatively large for such a change. The decrease has been unusual also in that it happened during and have ceased just after the end of the large variation of the solar wind parameters. Its duration is short-lived, and its nature is different from the longer-lasting electric field decrease associated with the modification of atmospheric conductivity associated with changes in the cosmic rays after solar flares. From the perspective of many years it is much more difficult to investigate such cases, since the related meteorological datasets that are stored are limited by their low time resolution. Nowadays, other resources are available at Swider, such as ceilometer measurements and automatic weather stations, and more frequent aerosol measurements that make the meteorological monitoring more accurate. Unfortunately, the rare magnetic storms in the current solar cycle provide few useful cases and coincidence with fair-weather conditions is also rare. An additional difficulty is the fact that solar wind conditions are different practically in each case.

\section{Diurnal Fair-Weather Electric Field Variations at Hornsund and Swider}

In the studies of SW-M-I effects on ground-level atmospheric electricity, a comparison with observations from other stations, for example, those placed at along a meridian at different latitudes, is especially interesting and useful. The studies of how far the effects of the large disturbances propagate and manifest themselves also at lower latitudes need further simultaneous observations in a network configuration. Having at our disposal observations from three latitudinal stations (Hornsund, Marsta, Swider), we have rarely found a coincidence of fair weather at Hornsund and Swider, and unfortunately we were not able to compare it with corresponding variations from Marsta because the fair-weather conditions have not been fulfilled in those cases. Below are presented only some examples of the groundlevel electric field $E_{z}$ at Hornsund and Swider at the coincidence of fair-weather conditions at both stations simultaneously during full $24 \mathrm{~h}$ of a day. Figure 13a shows the recordings on 13 June 2011, and Fig. 13b shows another, similar case of 05 June 2011. These two cases are examples of fair-weather and magnetically disturbed days when the local K-index has risen to 4-6. Examples of $E_{z}$ variations on fair-weather and magnetically quiet days, of K-index between 0 and 2, on 23 Apr 2009, and on 11 May 2011, are shown in Fig. 13c and d, respectively.

The time of the minimum and maximum of the field at Swider is usually in fair agreement with the global average represented by the Carnegie curve and the Swider long-term average $E_{z}$ variation shown in Figs. 14 and 15 b (discussed below). A morning increase of the field is present at both Swider and in Hornsund. During daytime, the field increase at Swider can be hampered due to the appearance and increase of the vertical air-masses exchange which is considered to be responsible for the deep daytime depression till $\sim 18$ 

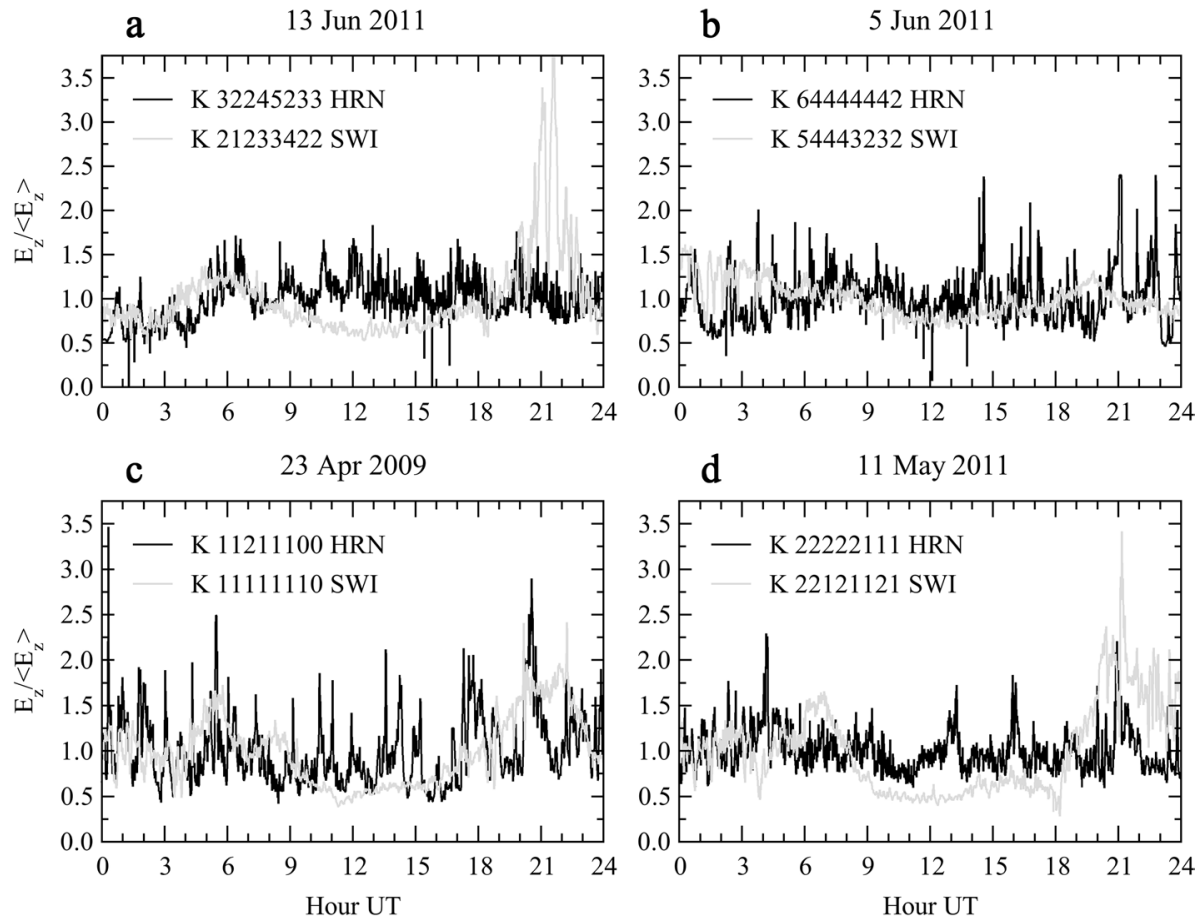

Fig. 13 Diurnal variations of atmospheric electric field in fair-weather conditions simultaneously occurring at Hornsund and at Swider stations. For better comparison, values reduced by mean value: a 13 June 2011, b 5 June 2011, c 23 April 2009, d 11 May 2011. Corresponding values of 3-h (local) K-index at Hornsund (HRN) and at Belsk for Swider station (SWI) station are displayed in the legends

UT, clearly visible in the average "Summer" curve. At Hornsund, the initial increase is probably continued due the positive dawn excursion of the electric potential of the ionospheric convection and later the field remains fairly constant on average, since the warming of the ground is weak and the vertical air mass exchange effect is smaller at polar latitudes. The expected global maximum at $\sim 20-21$ UT is often absent at Hornsund. This in turn may be due to the enhanced effect of the negative bay of the ionospheric convection potential affecting the field at ground level during increased solar wind disturbance. At Swider, an increase of the electric field is often also due to aerosol and local pollution, especially in the winter. The increase of the field on 13 June 2011 about $\sim 20$ UT could as well be caused by sudden increase of aerosol concentration as recorded on that day. A high correlation of $E_{z}$ between Hornsund and Swider is seldom. In other cases, there is even less similarity or correlation in the simultaneously measured signals. The number of days of simultaneous fair-weather at both Swider and Hornsund per year is about 10. Taking into account the magnetically quiet conditions, there may be even less such days. When considering periods of fair weather of shorter duration, the number of such cases increases but is still not very high.

Further differences between $E_{z}$ behaviour at the two stations are revealed by statistical curves. Statistical variations presented here are based on data from the years 2004-2011 since earlier recordings have not always been available in a digital form or could not be converted from original data. Figures 14 and 15 show average diurnal variations of $E_{z}$ 
Fair-weather electric field mean diurnal variation (2004-2011) _ _ Disturbed

a

HRN

b Quiet
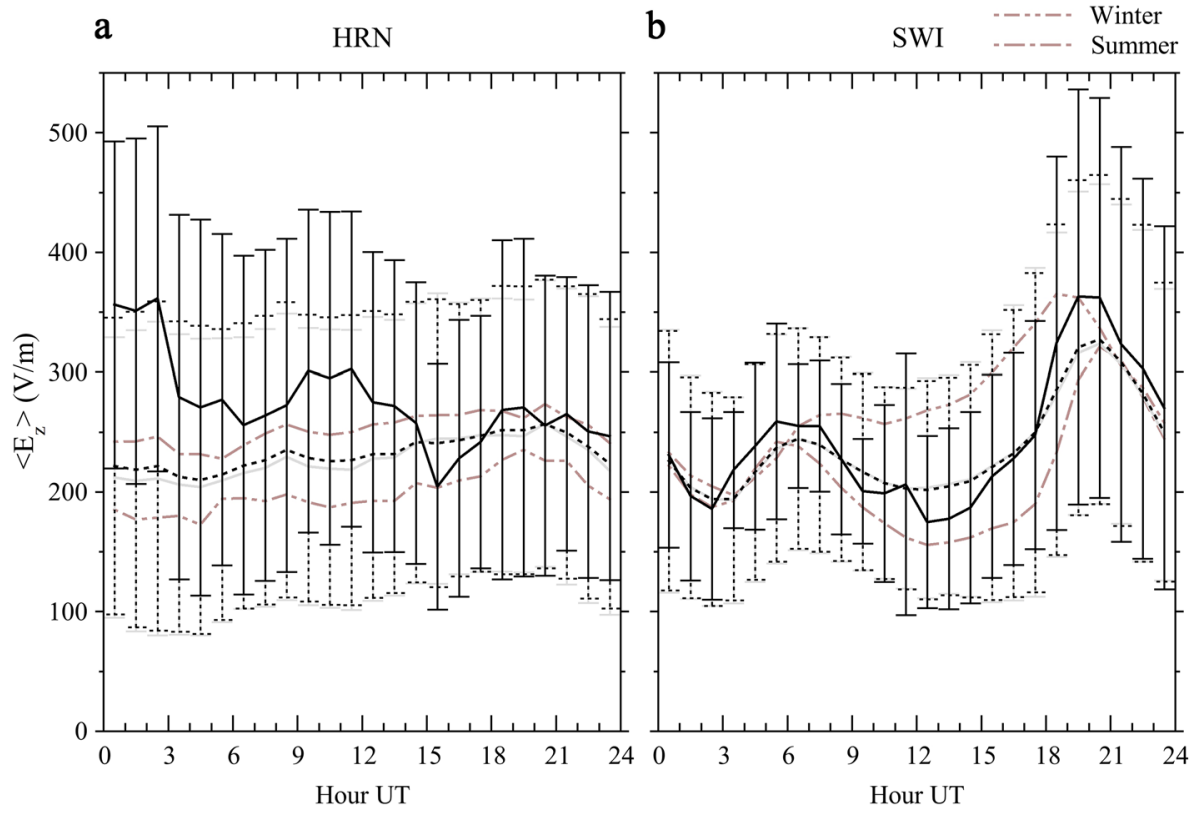

Fig. 14 Mean diurnal variations of atmospheric electric field in fair-weather conditions at Hornsund (a) and Swider (b) station. Brown curves named "Summer" and "Winter" in each panel show seasonal differences and are based on recordings from March to August and September-February (2004-2011), respectively. Grey and black curves refer to level of magnetic activity determined by daily average 3-h K-index, in ranges 0-3 ("Quiet") and 4-9 ("Disturbed"). Black dashed curve is the all-year mean variation for all levels of magnetic activity. Curves are composed of hourly mean average values at fair-weather conditions on days with at least $12 \mathrm{~h}$ of fair weather. Error bars indicate standard deviations. Hornsund data are not reduced to flat area value

separately at Hornsund and Swider stations calculated for two half-year seasons and two arbitrary levels of magnetic activity, in addition to a general average variation in these years. Curves are composed of hourly average values of the electric field measured on days with at least $12 \mathrm{~h}$ of fair weather: curves in Fig. 14 consist of mean averages, and in Fig. 15 of median values divided by $24-\mathrm{h}$ median, i.e. these are reduced values. The fair-weather hours of 2004-2011 have been gathered from routinely prepared tables of fair weather hours at both stations for each month. The total average values and count of $E_{z}$ values contributing to the each of 24 hourly values in these statistical curves are shown in Table 1. The first two curves are seasonal curves named "Summer" and "Winter" which correspond to measurements during six months from March to August and September to February, respectively. The next two curves refer to rough estimate of low and high magnetic activities, determined from 3-h local K-index in ranges 0-3 for "Quiet" conditions, and 4-9 for "Disturbed" conditions. The black dashed curve represents all-year average mean variation at all levels of magnetic activity. In the case of Swider, aerosol concentration was also considered as a factor, and only days of average concentrations of cloud condensation nuclei lower than $20,000 / \mathrm{m}^{3}$ have been analysed [the relationships of aerosol concentrations and $E_{z}$ at Hornsund and at Swider have been studied by Kubicki et al. (2016)]. Local magnetic 
Fair-weather electric field mean diurnal variation (2004-2011)

All days

Disturbed

a
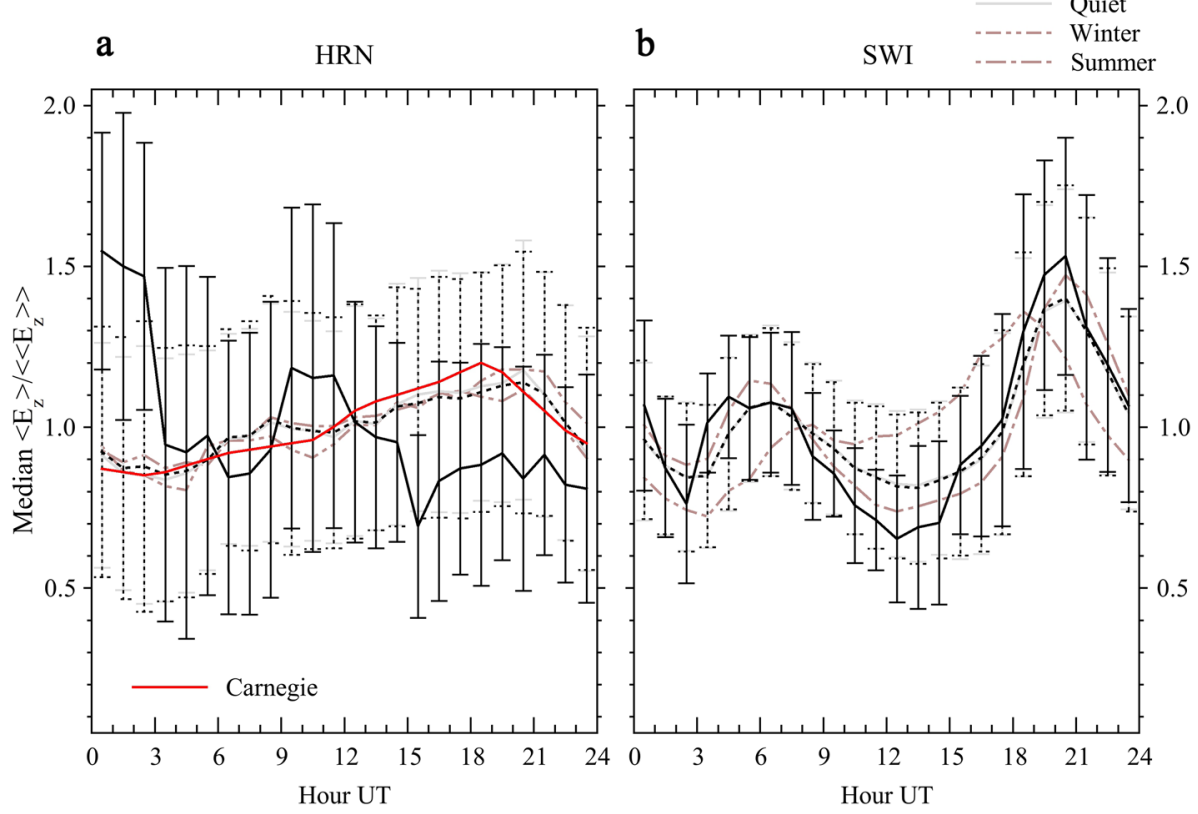

Fig. 15 Mean diurnal variations of atmospheric electric field in fair-weather conditions at Hornsund (a) and Swider (b) station. Diurnal variation of reduced hourly medians for Hornsund (HRN) and Swider (SWI). Brown, grey and black curves as described in Fig. 14. Errors bars indicate error for the reduced median where each median error is half of the interquartile range. The red curve in panel $\mathbf{a}$ is the reduced Carnegie curve as sampled in Israël (1973)

activity level has been determined from Belsk station (50 km off Swider). Standard deviations of hourly $E_{z}$ values at Swider are slightly less than at Hornsund-but overall variability is high. In the case of medians (Fig. 15), we calculated absolute errors as half of the interquartile range. These have been only slightly lower than standard deviation errors shown in Fig. 14. From the analysis, we see that at Hornsund the maximum value of the all-day average curve is only $15 \%$ of the total average value, and minimum is $15 \%$ smaller. The errors for each hourly value are high, of the order of 30-56\%. In the individual cases, the standard deviations are even more prominent. At Swider, the departure of maximum at 21 UT from the daily mean is $\sim 40 \%$ and the minimum at 3 UT is $19 \%$ smaller. Errors are of the order of 20-50\%. Comparison with the reduced Carnegie curve displayed in Fig. 15a shows that the long-term $E_{z}$ average variation at Hornsund is much closer to the Carnegie curve than the Swider curve is, but the Carnegie minimum and maximum are $\sim 1$ h earlier.

Seasonal effects at Swider are different than in Hornsund where there is a difference in amplitude in accordance with the maximum of the GEC in Northern Hemisphere summer (Adlerman and Williams 1996), while at Swider the winter pollution is an issue and enhances the mean amplitude of the field (see Fig. 14). Diurnal and seasonal variations at Swider have been described by Kubicki et al. (2007) and will not be further discussed here, as we concentrate on the disturbed diurnal variation of $E_{z}$ at Hornsund and Swider on magnetically active times associated with SW-M-I events. Compared with Hornsund, low magnetic activity is a less significant factor than seasonal differences in the relative 
Table 1 Average mean and median for the diurnal curves of fair-weather electric field, $E_{z}$, at Hornsund (HRN) and Swider (SWI) station

\begin{tabular}{|c|c|c|c|c|c|}
\hline \multirow{3}{*}{$\begin{array}{l}\text { Station } \\
\text { Period }\end{array}$} & \multicolumn{5}{|l|}{ HRN } \\
\hline & $\mathrm{V} / \mathrm{m}$ Mean & $\mathrm{V} / \mathrm{m}$ Median & Count & Count & Count \\
\hline & average* & average* & days $\mathrm{FF}(\mathrm{d})$ & hour Min (h) & hour Max (h) \\
\hline All days & 232 & 199 & 257 & 164 & 219 \\
\hline Summer & 252 & 221 & 160 & 105 & 133 \\
\hline Winter & 199 & 168 & 97 & 61 & 86 \\
\hline Quiet & 227 & 196 & 253 & 135 & 203 \\
\hline Disturbed & 276 & 256 & 92 & 11 & 44 \\
\hline \multirow{3}{*}{$\begin{array}{l}\text { Station } \\
\text { Period }\end{array}$} & \multicolumn{5}{|l|}{ SWI } \\
\hline & $\mathrm{V} / \mathrm{m}$ Mean & $\mathrm{V} / \mathrm{m}$ Median & Count & Count & Count \\
\hline & average & average & days FF (d) & hour Min (h) & hour Max (h) \\
\hline All days & 237 & 213 & 286 & 255 & 273 \\
\hline Summer & 214 & 201 & 167 & 156 & 164 \\
\hline Winter & 273 & 249 & 119 & 95 & 111 \\
\hline Quiet & 237 & 212 & 286 & 241 & 260 \\
\hline Disturbed & 243 & 222 & 69 & 6 & 26 \\
\hline
\end{tabular}

* Data from Hornsund are not reduced to flat area value

Third column indicates the number of days with at least $12 \mathrm{~h}$ of fair weather (FF) in 2004-2011 that contributed to the calculated variations of $E_{z}$

Fourth and fifth columns indicate minimum and maximum of an hour-equivalent count of 1-min $E_{z}$ values contributing to an hourly value displayed in Figs. 14 and 15

difference between all-days, quiet and disturbed curves. The Swider disturbed curve is characterised by slightly elevated field values, especially at 18-21 UT, and a period of decreased values at 12-15 UT. The reduced values in the local afternoon and evening could be explained by the discovered effects of magnetic storms reviewed in Sect. 3.3. In a model calculation of global change of ionospheric potential due to the ionospheric convection by Matveev et al. (1981) at $\Phi=50^{\circ}$ a positive deviation is predicted for $\sim 9-15 \mathrm{LT}$, but the Swider results do not confirm it.

At Hornsund, the diurnal variation of $E_{z}$ on disturbed days curve has an opposite trend than the all-day diurnal $E_{z}$ curve. It has elevated values in the first half of a UT-day with a maximum in the early, 00-03 UT period, and another, lower maximum at 09-12 UT. A minimum occurs at 15-16 UT. We can assume that the big maximum and the minimum can be associated with the behaviour of the ionospheric potential above the place due to ionospheric convection, which exhibits positive deviations in the morning and late evening hours and negative deviations at universal noon and afternoon. This effect was investigated for Hornsund at quiet days by Odzimek et al. (2011), shown in Fig. 2. It is also possible that the early morning increase is enhanced by the effect of the morning substorms (Kleimenova et al. 2011). The maximum in the middle of the day could instead be attributed to the effects of NBZ current systems, as discussed in Sect. 3.2. These effects, revealed by the statistical curves, confirm the findings from individual day analysis and perhaps their explanation would not be straightforward without earlier case studies. 
The average variations are presented here mainly as a reference to the individual events of the SW-M-I effects which are usually discerned using the procedure of subtracting the contribution of global GEC effects of the lower-atmosphere origin from the measured ground-level values during fair-weather periods. In many previously reported individual events, as a reference to the examined $E_{z}$ and $J_{z}$ values, their corresponding local fairweather average variations were used. In such a way, the contribution of SW-M-I effects cannot be always recognised, since, as it is also required, the corresponding fair-weather reference values have to simultaneously correspond to quiet magnetic conditions. The coincidence of meteorological fair-weather days with magnetically quiet conditions is at Hornsund rather rare. Nevertheless, at long-term recordings a considerable number of hours fulfilling the criteria have been found.

\section{Discussion}

We have reviewed the observed effects in atmospheric electricity at Hornsund and Swider stations considered as examples of influences of the interaction of the solar wind and the Earth's magnetosphere and ionosphere which further propagate downwards to the lower atmosphere. The effects mainly concern changes of the ground-level atmospheric field, $E_{z}$, and, to lesser extent, changes in ground-level atmospheric current density, $J_{z}$. They are presented as case studies in Sects. 2-3 as well as statistically in Sect. 4. We now qualitatively summarise the results in Table 2. The effects are divided into two types: when the amplitude of the field increases, i.e. the effect is a positive deviation, or the amplitude of the field decreases, i.e. the effect is a negative deviation of the field.

The local time variation of the ionospheric convection at the location of Hornsund is a source of positive deviations, present on average from midnight through morning and pre-noon time (dawn), and negative deviations post-noon and in the evening (dusk). As the ionospheric convection is enhanced during disturbed times, the field enhancements are observed during morning substorms and caused by Hornsund being under the positive cell of the ionospheric convection and sometimes at the footprint of inflowing R1 field-aligned currents. Some positive deviations have also been observed in the evening at quiet times, and these have been attributed to the decrease in size of the polar cap even if the magnitude of the convection measured by the cross-polar cap potential remains at similar levels. A particular type of positive deviations of $E_{z}$ is that associated with the development of R0/ NBZ current system at local noon at northern IMF $B_{z}$. The increase of the field is then attributed to Hornsund being at the footprint of the inflowing field-aligned current of the NBZ system.

Negative deviations seem to be more difficult to distinguish in the course of groundlevel atmospheric electric field variation, which also undergoes its diurnal cycle of global changes of the atmospheric electric circuit. A comparison with preceding or average quiet field level allowed to detect negative deviation of the field at Swider during main phase of a magnetic storm in the local daytime. The origin of this rather immediate decrease remains unexplained, but one of the proposed factors, in addition to conductivity-induced variations, was a field-induced origin - the penetration of the IMF electric field to the lowlatitude ionosphere during main phase of a magnetic storm (Huang et al. 2005). A longer decrease of the electric field during magnetic storms, in the first $\sim 12$-h period or more prolonged (several days), was earlier attributed to modification of atmospheric conductivity due to changes in the cosmic rays cutoff rigidity and to Forbush effects. 
Table 2 Types of SW-M-I-induced disturbances of ground-level atmospheric electric observed at different local time and latitudes and their assumed sources: "+" positive deviations, i.e. the amplitude of the field increases, "-" negative deviations, i.e. the amplitude of the field decreases

\begin{tabular}{|c|c|c|c|c|c|c|}
\hline Station & Conditions & Midnight & Dawn & Noon & Dusk & Sources \\
\hline \multirow{4}{*}{$\begin{array}{l}\text { Hornsund } \\
\text { (High latitudes) }\end{array}$} & Quiet & & + & & - & Ionospheric convection (IC) \\
\hline & & & & & + & $\begin{array}{l}\text { Change of magnitude and size } \\
\text { of IC }\end{array}$ \\
\hline & Substorms & + & + & & - & $\begin{array}{l}\text { Under projection of intensified } \\
\text { IC cell or footprint of R1 } \\
\text { FACs }\end{array}$ \\
\hline & & & & + & & $\begin{array}{l}\text { At the footprint of inflowing } \\
\text { R0/NBZ FACs }\end{array}$ \\
\hline Swider & $\begin{array}{l}\text { Magnetic } \\
\text { storms }\end{array}$ & & & - & - & \\
\hline (Middle latitudes) & & & & & & \\
\hline
\end{tabular}

In general, the review of the electric field and current variation events presented in Sects. 2-3 with some preliminary remarks on many influences of the contemporary solar wind changes need to be considered in greater detail. If one expects the $E_{z}$ and $J_{z}$ variations to be able to deliver supplementary information on the examined relationships, even from one site, then the problems with the identification and separation of single effects have to be recognised and significantly reduced (Michnowski 1998). At a particular site, the determination of local disturbances at fair weather conditions demands simultaneous meteorological and other environmental parameter monitoring. At Hornsund, and in a larger extent at Swider, such control has been considered fairly feasible. It is worth reminding that due to the drastically, about $10^{7}$ times, smaller energy rate delivered by solar wind than by the electromagnetic heat rate, these examined influences are difficult to be detected in spite of the fact that the delivered solar wind energy is extremely more changeable in time (Tinsley 1994). The identification and evaluation of the solar wind induced component in the recorded $E_{z}$ and $J_{z}$ values requires a careful detailed segregation of the data at different situations. The rejection of those in which the other effects are distinctly large is common, especially in searching for the so-called fair weather conditions periods in which the strong local meteorological disturbances are minimised. Sometimes, a comparison with quiet fairweather conditions is applied. Local disturbances at Hornsund, as mentioned in Sect. 4, are high, even if one may expect the planetary boundary layer and convective air mass exchange responsible for the largest local fair weather effects to be small at high latitudes.

In spite of the above-mentioned obstacles, we have observed some interesting cases. Such an example of an individual case is the remarkable event of 2 March 1989 (Fig. 3) (Michnowski et al. 1991; Kleimenova et al. 1992), the description of which is worth revising. In this case the amplitude of the maximal deviation in this event from the average value was very high in relation to the previous signal level and to its average level. The observed anomaly in $E_{z}$ could have been, however, accidental even despite the fact that its magnitude, as shown in Sect. 3.1, was 1.6 times larger than the average $E_{z}$ values sustained before, during quiet magnetic conditions, for several hours. The deviation of the field value in the disturbed period from the mean value in the quiet period is almost twice higher than the standard deviation. Moreover, it is necessary to recall that the enhancement of the $E_{z}$ field was in strong coincidence with the corresponding rapid change of the solar wind components, $B_{z}$ and $B_{y}$. These circumstances gave grounds to believe that 
the demonstrated $E_{z}$ enhancement of 2 March 1989, was of the solar wind event origin. This case practically convinced us about the existence of evident physical dependence of ground-level electric parameters monitored by us on solar wind changes which resulted in further, detailed studies of many more events (Kleimenova et al. 2013). Another example of a large $E_{z}$ enhancement may be the case of the Bastille Day event on 14-16 June 2000 (Fig. 9) (Nikiforova et al. 2002; Kleimenova et al. 2008a). However, taking into account the different complex of circumstances, these examples are not directly comparable. The usually required repetition and regularity of the investigated phenomena, especially during large solar events, is for us practically unavailable - due to the simultaneous action of a very large number of influencing factors causing particular responses in the atmospheric electric field at the ground level, dependent on multitude of different physical parameters, as mentioned before.

A possibility to evaluate the $E_{z}$ and $J_{z}$ influences by the estimation of changes induced by solar wind in the ionospheric potential and integrated columnar conductivity (between the ionosphere and the Earth's surface) above the site is practically unavailable, mainly because of the great number of complex, multilateral influencing factors, the monitoring of which is difficult or even impossible with required certainty or resolution. Using the before mentioned and widely applied extraction of all other influences from the electric signal needs, at first, the basic evaluation of the local effects that can be high even during fair weather periods. Obviously helpful are models which determine the distribution of the ionospheric potential due to ionospheric convection or field-aligned currents. Unfortunately, these models often suffer from limited resolution compared with ground-level recordings. Such difficulties contribute to the fact that so far quantitative explanation of the observed effects in Hornsund or Swider in individual cases has not been particularly achieved (Michnowski et al. 2007; Kleimenova et al. 2011; Frank-Kamenetskii et al. 2012; Kubicki et al. 2014).

More information is obviously needed to find the direct cause or causes of the examined deviations in each case. Some insights into the causes of the effect observed at a given point seems to be available because they are integrally reflected in the actual ionospheric potential, field-aligned currents and spatial configuration of energetic particles directly responsible for such effects. Experimental monitoring of $E_{z}$ changes can be supported by theoretical approach using models such as, for example, Milan (2013). Numerical methods and contemporary computer facilities enabled a fast development of SW-M-I coupling models important for space weather forecast (Koskinen et al. 2017). The presently attainable data on these factors from ground-based magnetometer networks, polar radar systems and satellite measurements, cover huge areas at a planetary scale. For example, the new AMPERE project determines the field-aligned currents from magnetometers on board a large network of satellites, with high spatial and time resolution (Anderson et al. 2014). The use of modern facilities would be helpful in the consideration of the events, such as that of 2 March 1989, which we have analysed using ground-based magnetometer measurements and ionospheric potential modelling based on hourly IMF and plasma data. The satellite and radar methods allowed to model the ionospheric convection potential (Fig. 3), although in this case it was impossible to recreate it with higher time resolution because of low resolution of solar wind data available from that period. Although such a time resolution can be obtained with the indirect inversion, the magnetic field recordings from a large number of ground-based geomagnetic observatories, the so-deduced potentials suffer from uncertainties due to the lack of reliable data on the ionospheric conductivity (Kamide et al. 1994). Recently, such a possibility has appeared to be available due to the new satellite method of auroral monitoring by THEMIS (Lam et al. 2019). More recent events can be 
analysed with the help of the potential modelling based on radar data of higher time resolution such as provided by present SuperDARN (Nishitani et al. 2019). The SuperDARN also extends its facilities in order to be able to study lower-latitude phenomena and large magnetospheric disturbances (Baker et al. 2007; Clausen et al. 2012; Walach and Grocott 2019). It is anticipated that an extended spatial range of SuperDARN radars may support further studies on topics considered in this paper (Odzimek 2019b).

\section{Conclusion}

It is still unclear which of the ways to explain the coupling between the solar wind and magnetosphere and ionosphere gives better understanding of the electric potential distribution in the ionosphere and further the effect on the lower-atmosphere electrical parameters. Theoretical treatments are obviously required. The latest facilities and methods available in the computer science are promising in this respect. They can be now supported by promising novel satellite observations such as those proposed in the AMPERE project providing better evaluation of the field-aligned currents. Extended research in this direction may lead to better understanding of the very complex various phenomena and processes acting in the coupling between the SW-M-I. Understanding of the relationships between the above-mentioned coupling and the electric parameters of the lower atmosphere remains incomplete. Still, the ground-based recordings of the electric field and current, which are inexpensive and practically available, are worth to be applied to continuous monitoring of these important processes. Numerous examples of effects of the conducting ionosphere and magnetosphere have been shown in our review. These effects have been observed in a relatively thin layer at the ground of weakly ionised, less conductive air. Atmospheric electricity research often limits its interest to this thin region, while the understanding of the electric behaviour of the Earth as a whole system remains a challenge.

Acknowledgements Authors would like to thank Marcin B. Kaczorowski who assisted S.M. in the work on the manuscript and Aleksandra Holda-Michalska for the graphic work on Figure 1. We deeply thank Anna Dziembowska for language corrections of the manuscript, advice, and long-lasting support. We also express deep gratitude to anonymous Reviewers of this paper. We acknowledge the Institutes who maintain the IMAGE Magnetometer Array: Tromso Geophysical Observatory of UiT the Arctic University of Norway (Norway), Finnish Meteorological Institute (Finland), Institute of Geophysics Polish Academy of Sciences (Poland), GFZ German Research Centre for Geosciences (Germany), Geological Survey of Sweden (Sweden), Swedish Institute of Space Physics (Sweden), Sodankylä Geophysical Observatory of the University of Oulu (Finland), and Polar Geophysical Institute (Russia). We also acknowledge the institutions who maintain the INTERMAGNET magnetometer stations, particularly: Geological Survey of Canada, United States Geological Survey, Technical University of Denmark, and Institute of Geophysics, Polish Academy of Sciences. Authors give credit to NASA Space Physics Data Facility and OMNI project for data obtained from OMNIWeb interface, and OVATION project at The Johns Hopkins University, Applied Physics Laboratory, for DSMP OVATION auroral oval position data and SuperDARN ionospheric convection plots, both made available online. Polish Polar Station in Hornsund (Svalbard, Norway) is operated by the Institute of Geophysics, Polish Academy of Sciences (IGF PAS), and supported by SPUB Grants from Ministry of Science and Higher Education of Poland. Atmospheric electricity measurements at Hornsund and relevant databases are maintained by S. Kalinowski Geophysical Observatory of IGF PAS at Świder. Support for this work has been provided by Poland Ministry of Science and Higher Education (now Ministry of Education and Science) through subsidies to Institute of Geophysics, Polish Academy of Sciences.

\section{Declarations}

Conflict of interest The authors declare that they have no conflict of interest. 
Open Access This article is licensed under a Creative Commons Attribution 4.0 International License, which permits use, sharing, adaptation, distribution and reproduction in any medium or format, as long as you give appropriate credit to the original author(s) and the source, provide a link to the Creative Commons licence, and indicate if changes were made. The images or other third party material in this article are included in the article's Creative Commons licence, unless indicated otherwise in a credit line to the material. If material is not included in the article's Creative Commons licence and your intended use is not permitted by statutory regulation or exceeds the permitted use, you will need to obtain permission directly from the copyright holder. To view a copy of this licence, visit http://creativecommons.org/licenses/by/4.0/.

\section{References}

Adlerman EJ, Williams ER (1996) Seasonal variation of global electric circuit. J Geophys Res 101(D23):29679-29688. https://doi.org/10.1029/96JD01547

Afonina R, Bandilet O, Belov B, Kanonidi K, Levitin A, Chernysheva S, Sheftel V (1985) Variations of the atmospheric electric field Ez, controlled by $\mathrm{Bz}$ and $\mathrm{By}$ components of the interplanetary magnetic field. Geomagn Aeron 25(1):167-169

Akasofu SI, Chapman S (1959) The sudden commencements of geomagnetic storms. URANIA 44(250):321-358

Anderson BJ, Korth H, Waters CL, Green DL, Merkin VG, Barnes RJ, Dyrud LP (2014) Development of large-scale Birkeland currents determined from the Active Magnetosphere and Planetary Electrodynamics Response Experiment. Geophys Res Lett 41(9):3017-3025. https://doi.org/10.1002/2014G L059941

Anisimov SV, Morgunov VA, Troitskaya VA (1991) Substorms of potential gradient of the atmospheric electric field. In: Michnowski S, Ruhnke LH (eds) Proceedings of the International workshop on global atmospheric electricity measurements, 10-16 September 1989, Madralin, Poland, Publs Inst Geophys Pol Acad Sci 238(D-35):77-83

Apsen AG, Kanonidi KD, Chernyshova SP, Chetaev DN, Scheftel VM (1988) Magnetospheric effects in atmospheric electricity. Publications of the SSSR Academy of Sciences, Institute of Terrestrial Magnetism, Ionosphere and Radio-Wave Propagation, Nauka, Moscow

Araki T (1994) A Physical Model of the Geomagnetic Sudden Commencement, American Geophysical Union (AGU), pp 183-200. https://doi.org/10.1029/GM081p0183

Baker JBH, Greenwald RA, Ruohoniemi JM, Oksavik K, Gjerloev JW, Paxton LJ, Hairston MR (2007) Observations of ionospheric convection from the Wallops SuperDARN radar at middle latitudes. J Geophys Res. https://doi.org/10.1029/2006JA011982

Bandilet O, Chernysheva S, Sheftel V (1982a) The vertical component of the geoelectrical field at high latitudes and processes in the magnetosphere. Geomagn Aeron 22(2):252-256

Bandilet O, Frank-Kamenetsky A, Chernysheva S, Sheftel V (1982b) The spatial distribution of disturbances of the vertical component of the geoelectric field, accompanying an intensification of magnetic activity. Geomagn Aeron 22(6):1029-1030

Bandilet OI, Kozelova TV, Chernysheva SP, Sheftel VM (1982c) About the nature of the vertical component of the electric field during the magnetic disturbances. Geomagn Aeron 22(6):1028-1029

Bandilet O, Chernysheva S, Sheftel V (1985) Variations of the atmospheric electric field at high latitudes during geomagnetic disturbances. Geomagn Aeron 25(4):628-632

Bandilet OI, Kanonidi KD, Chernysheva SP, Sheftel VM (1986) Effects of magnetospheric substorms in the atmospheric electric field. Geomagn Aeron 26(1):159-160

Bartels J, Heck NH, Johnston HF (1939) The three-hour-range index measuring geomagnetic activity. Terr Magn Atmos Electr 44(4):411-454. https://doi.org/10.1029/TE044i004p00411

Bazilevskaya GA, Usoskin IG, Flückiger EO, Harrison RG, Desorgher L, Bütikofer R, Krainev MB, Makhmutov VS, Stozhkov YI, Svirzhevskaya AK, Svirzhevsky NS, Kovaltsov GA (2008) Cosmic ray induced ion production in the atmosphere. Space Sci Rev 137(1):149-173. https://doi.org/10.1007/ s11214-008-9339-y

Behlke R (2016) The Danish Greenland magnetometer chain-status and outlook. AGU Fall Meeting Abstracts, SH11C-2274

Belova E, Kirkwood S, Tammet H (2000) The effect of magnetic substorms on near-ground atmospheric current. Ann Geophys 18(12):1623-1629. https://doi.org/10.1007/s00585-001-1623-Z

Bering EA III (1995) The global circuit: global thermometer, weather by-product or climatic modulator? Rev Geophys 33(S2):845-862. https://doi.org/10.1029/95RG00549 
Bering EA III, Benbrook JR, Byrne GJ, Liao B, Theall JR, Lanzerotti LJ, Maclennan CG, Wolfe A, Siscoe GL (1988) Impulsive electric and magnetic field perturbations observed over south pole: flux transfer events? Geophys Res Lett 15(13):1545-1548. https://doi.org/10.1029/GL015i013p01545

Bering EA III, Few AA, Benbrook JR (1998) The global electric circuit. Phys Today. https://doi.org/10. $1063 / 1.882422$

Bering III EA, Benbrook JR, Byrne GJ, Few AA (1991) Measurements of vertical atmospheric electric current at a network of sites in Antarctica including manned stations and automatic geophysical observations. In: Michnowski S, Ruhnke LH (eds) Proceedings of the International workshop on global atmospheric electricity measurements, 10-16 September 1989, Madralin, Poland, Publs Inst Geophys Pol Acad Sci 238(D-35):119-135

Berlinski J, Pankanin G, Kubicki M (2007) Large scale monitoring of troposphere electric field. In: Proceedings of the 13th International conference on atmospheric electricity, 13-17 August 2007, vol I, Beijing, China, pp 124-126

Borovsky JE (2020) What magnetospheric and ionospheric researchers should know about the solar wind. J Atmos Sol Terr Phys 204:105271. https://doi.org/10.1016/j.jastp.2020.105271

Borovsky JE, Valdivia J (2018) The Earth's magnetosphere: a systems science overview and assessment. Surv Geophys 39:817-859. https://doi.org/10.1007/s10712-018-9487-x

Bostrom R, Fahleson U (1977) Vertical propagation of time-dependent electric fields in the atmosphere and ionosphere. In: Dolezalek H, Reiter R, Landsberg H (eds) Electrical processes in atmospheres, Proceedings of the 5th International conference on atmospheric electricity, Garmisch-Partenkirchen, Germany, 2-7 September 1974, Steinkopff, Heidelberg, pp 529-535. https://doi.org/10.1007/978-3642-85294-7_82

Burns GB, Hessea MH, Parcella SK, Malachowski S, Coleb KD (1995) The geoelectric field at Davis station, Antarctica. J Atmos Terr Phys 57(14):1783-1797. https://doi.org/10.1016/0021-9169(95) 00098-M

Burns GB, Frank-Kamenetsky A, Bering EA, Papitashvili VO, Troshichev OA (1998) The geoelectric field: a link between the troposphere and solar variability. Ann Glaciol 27:651-654. https://doi.org/10.3189/ 1998AoG27-1-651-654

Burns GB, Tinsley BA, Frank-Kamenetsky AV, Bering EA (2007) Interplanetary magnetic field and atmospheric electric circuit influences on ground-level pressure at Vostok. J Geophys Res Atmos. https:// doi.org/10.1029/2006JD007246

Chisham G, Lester M, Milan SE, Freeman MP, Bristow WA, Grocott A, McWilliams KA, Ruohoniemi JM, Yeoman TK, Dyson PL, Greenwald RA, Kikuchi T, Pinnock M, Rash JPS, Sato N, Sofko GJ, Villain JP, Walker ADM (2007) A decade of the Super Dual Auroral Radar Network (SuperDARN): scientific achievements, new techniques and future directions. Surv Geophys 28:33-109. https://doi.org/10. 1007/s10712-007-9017-8

Chrobak M, Drogoń R, Michnowski S (1984) Dynamiczny uklad stacyjny do pomiaru natezenia pola elektrycznego przy powierzchni ziemi w warunkach polarnych (A station field mill for continuous work in polar conditions). Archives of Institute of Geophysics, Polish Academy of Sciences, Warsaw

Clauer CR, Banks PM (1986) Relationship of the interplanetary electric field to the high-latitude ionospheric electric field and currents: observations and model simulation. J Geophys Res Space 91(A6):6959-6971. https://doi.org/10.1029/JA091iA06p06959

Clausen LBN, Baker JBH, Ruohoniemi JM, Greenwald RA, Thomas EG, Shepherd SG, Talaat ER, Bristow WA, Zheng Y, Coster AJ, Sazykin S (2012) Large-scale observations of a subauroral polarization stream by midlatitude SuperDARN radars: instantaneous longitudinal velocity variations. J Geophys Res Space. https://doi.org/10.1029/2011JA017232

Cliver EW, Kahler SW, Shea MA, Smart DF (1982) Injection onsets of $2 \mathrm{GeV}$ protons, $1 \mathrm{MeV}$ electrons, and $100 \mathrm{keV}$ electrons in solar cosmic ray flares. Astrophys J 260:362-370

Corney RC, Burns GB, Michael K, Frank-Kamenetsky AV, Troshichev OA, Bering EA, Papitashvili VO, Breed AM, Duldig ML (2003) The influence of polar-cap convection on the geoelectric field at Vostok, Antarctica. J Atmos Sol Terr Phys 65(3):345-354. https://doi.org/10.1016/S1364-6826(02) 00225-0

Cowley SWH (1995) The Earth's magnetosphere: a brief beginner's guide. Eos Trans AGU 76(51):525529. https://doi.org/10.1029/95EO00322

D’Angelo N, Iversen IB, Madsen Mohl M (1982) Influence of the dawn-dusk potential drop across the polar cap on the high-latitude atmospheric vertical current. Geophys Res Lett 9(7):773-776. https://doi.org/ 10.1029/GL009i007p00773

Davis TN, Sugiura M (1966) Auroral electrojet activity index AE and its universal time variations. J Geophys Res 71(3):785-801. https://doi.org/10.1029/JZ071i003p00785 
Dorman LI (2019) Energetic particles and auroras in magnetosphere/ionosphere. Nova Science Publishers, Hauppauge

Dungey JW (1961) Interplanetary magnetic field and the auroral zones. Phys Rev Lett 6(2):47-48. https:// doi.org/10.1103/PhysRevLett.6.47

Dziembowska A (2009) Eighty years of fair-weather atmospheric electricity monitoring at Świder in Poland. Publ Inst Geophys Pol Acad Sci 412(D-73):9-14. https://pub.igf.edu.pl/recent-developmentsin-atmospheric-electricity-publication-to-commemorate-the-90th-birthday-of-stanislaw-michnowski ,4,en,pubs, 4,0,4,20.html

Elhalal G, Yair Y, Nicoll K, Price C, Reuveni Y, Harrison RG (2014) Influence of short-term solar disturbances on the fair weather conduction current. J Space Weather Space Clim 4:A26. https://doi.org/10. $1051 / \mathrm{swsc} / 2014022$

Frank-Kamenetsky AV, Kalita VM (1986) Sviaz variacji atmosfernogo elektricheskogo pola v polarnoj shapke s parametrami MPP. In: Frank-Kamenetsky AV (ed) Geofizicheskie issledovania v visokih shirotah. Geophysical research at high latitudes, Trans Arc Ant Res Inst 405:48-56

Frank-Kamenetsky AV, Burns GB, Troshichev OA, Papitashvili VO, Bering EA, French WJR (1999) The geoelectric field at Vostok, Antarctica: its relation to the interplantary magnetic field and the cross polar cap potential difference. J Atmos Sol Terr Phys 61(18):1347-1356. https://doi.org/10.1016/ S1364-6826(99)00089-9

Frank-Kamenetsky AV, Troshichev OA, Burns G, Papitashvili VO (2001) Variations of the atmospheric electric field in the near-pole region related to interplanetary magnetic field. J Geophys Res Space 106(A1):179-190. https://doi.org/10.1029/2000JA900058

Frank-Kamenetskii AV, Kotikov AL, Kruglov AA, Burns GB, Kleimenova NG, Kozyreva O, Kubitski M, Odzimek A (2012) Variations in the near-surface atmospheric electric field at high latitudes and ionospheric potential during geomagnetic perturbations. Geomagn Aeron 52(5):629-638. https://doi.org/ 10.1134/S0016793212050064

Freier GD (1961) Auroral effects on the Earth's electric field. J Geophys Res 66(9):2695-2702. https://doi. org/10.1029/JZ066i009p02695

Glegolski W, Gnoiński A (2005) Results of geomagnetic observations, Polish Polar Station, Hornsund, Spitsbergen, 2004. Publ Inst Geophys Pol Acad Sci 380(C-93)

Glegolski W, Gnoiński A (2006) Results of geomagnetic observations - Polish Polar Station Hornsund, Spitsbergen, 2005. Publ Inst Geophys Pol Acad Sci 393(C-97)

Gołkowski M (2019) HAARP — a unique facility for geophysical research. Prz Geof 64(3-4):287-303. https://doi.org/10.32045/PG-2019-010

Gonzalez WD, Joselyn JA, Kamide Y, Kroehl HW, Rostoker G, Tsurutani BT, Vasyliunas VM (1994) What is a geomagnetic storm? J Geophys Res Space 99(A4):5771-5792. https://doi.org/10.1029/93JA0 2867

Gopalswamy N, Xie H, Yashiro S, Akiyama S, Mäkelä P, Usoskin IG (2012) Properties of ground level enhancement events and the associated solar eruptions during solar cycle 23. Space Sci Rev 171(1):23-60. https://doi.org/10.1007/s11214-012-9890-4

Greenwald RA, Baker KB, Dudeney JR, Pinnock M, Jones TB, Thomas EC, Villain JP, Cerisier JC, Senior C, Hanuise C, Hunsucker RD, Sofko G, Koehler J, Nielsen E, Pellinen R, Walker ADM, Sato N, Yamagishi H (1995) DARN/SuperDARN. Space Sci Rev 71(1):761-796. https://doi.org/10.1007/ BF00751350

Hairston MR, Heelis RA, Rich FJ (1998) Analysis of the ionospheric cross polar cap potential drop using DMSP data during the National Space Weather Program study period. J Geophys Res Space 103(A11):26337-26347. https://doi.org/10.1029/97JA03241

Hale L, Croskey C (1979) An auroral effect on the fair weather electric field. Nature 278:239-241. https:// doi.org/10.1038/278239a0

Hargreaves JK (1992) The solar-terrestrial environment. Cambridge University Press, Cambridge. https:// doi.org/10.1017/CBO9780511628924

Heppner J (1977) Empirical models of high-latitude electric fields. J Geophys Res 82(7):1115-1125. https:// doi.org/10.1029/JA082i007p01115

Herman JR, Goldberg RA (1978) Initiation of non-tropical thunderstorms by solar activity. J Atmos Terr Phys 40(2):121-134. https://doi.org/10.1016/0021-9169(78)90016-8

Hill TW, Dessler AJ, Wolf RA (1976) Mercury and Mars: the role of ionospheric conductivity in the acceleration of magnetospheric particles. Geophys Res Lett 3(8):429-432. https://doi.org/10.1029/GL003 i008p00429

Huang CS, Foster JC, Kelley MC (2005) Long-duration penetration of the interplanetary electric field to the low-latitude ionosphere during the main phase of magnetic storms. J Geophys Res Space. https://doi. org/10.1029/2005JA011202 
Iijima T, Potemra TA (1976) Field-aligned currents in the dayside cusp observed by Triad. J Geophys Res 81(34):5971-5979. https://doi.org/10.1029/JA081i034p05971

Iijima T, Potemra TA (1978) Large-scale characteristics of field-aligned currents associated with substorms. J Geophys Res Space Phys 83(A2):599-615. https://doi.org/10.1029/JA083iA02p00599

Iijima T, Potemra TA, Zanetti LJ, Bythrow PF (1984) Large-scale Birkeland currents in the dayside polar region during strongly northward IMF: a new Birkeland current system. J Geophys Res Space 89(A9):7441-7452. https://doi.org/10.1029/JA089iA09p07441

Imyanitov IM, Chubarina YV (1967) Electricity of free atmosphere. Gidrometeoizdat, Leningrad, 1965, Technical Translation from Russian, NASA, Washington, TT F-425

Israël H (1973) Atmospheric electricity, vol II, Fields, charges, currents. Israel Program for Scientific Translations, Jerusalem

Israelsson S, Tammet H (2001) Variation of fair weather atmospheric electricity at Marsta Observatory, Sweden, 1993-1998. J Atmos Sol Terr Phys 63:1693-1703. https://doi.org/10.1016/S1364-6826(01) 00049-9

Jankowski J (2007) Results of geomagnetic observations; Belsk, Hel, Hornsund, 2006. Publ Inst Geophys Pol Acad Sci 402(C-100). https://pub.igf.edu.pl/results-of-geomagnetic-observations-belsk-hel-horns und-2006,4,en,pubs, 4,0,3,31.html

Kalinowska-Widomska E (1977) Long-term changes in magnetic and atmospheric-electric fields on the basis of the recordings of the St. Kalinowski Geophysical Observatory at Swider, Poland. In: Dolezalek H, Reiter R, Landsberg H (eds) Electrical processes in atmospheres, Proceedings of the 5th International conference on atmospheric electricity, Garmisch-Partenkirchen, Germany, 2-7 September 1974, Steinkopff, Heidelberg, pp 736-739. https://doi.org/10.1007/978-3-642-85294-7_118

Kamide Y, Baumjohann W (1993) Magnetosphere-ionosphere coupling. Physics and chemistry in space planetology, SPACE, vol 23. Springer, Berlin. https://doi.org/10.1007/978-3-642-50062-6

Kamide Y, Richmond AD, Matsushita S (1981) Estimation of ionospheric electric fields, ionospheric currents, and field-aligned currents from ground magnetic records. J Geophys Res Space 86(A2):801813. https://doi.org/10.1029/JA086iA02p00801

Kamide Y, Richmond AD, Emery BA, Hutchins CF, Ahn BH, de la Beaujardiere O, Foster JC, Heelis RA, Kroehl HW, Rich FJ, Slavin JA (1994) Ground-based studies of ionospheric convection associated with substorm expansion. J Geophys Res Space 99(A10):19451-19466. https://doi.org/10.1029/ 94JA01625

Kamide Y, Yokoyama N, Gonzalez W, Tsurutani BT, Daglis IA, Brekke A, Masuda S (1998) Two-step development of geomagnetic storms. J Geophys Res Space 103(A4):6917-6921. https://doi.org/10. 1029/97JA03337

Kelley MC, Makela JJ (2002) By-dependent prompt penetrating electric fields at the magnetic equator. Geophys Res Lett 29(7):57-1-57-3. https://doi.org/10.1029/2001GL014468

Kepko L, McPherron RL, Amm O, Apatenkov S, Baumjohann W, Birn J, Lester M, Nakamura R, Pulkkinen TI, Sergeev V (2015) Substorm current wedge revisited. Space Sci Rev 190:1-46. https://doi.org/10. 1007/s11214-014-0124-9

Kivelson MG, Ridley AJ (2008) Saturation of the polar cap potential: inference from Alfvén wing arguments. J Geophys Res Space. https://doi.org/10.1029/2007JA012302

Kleimenova NG, Kozyreva OV, Michnowski S, Szymanski A, Ermolenko DY (1992) Vysokoshirotnye dlinnoperiodnye pulsatii $\mathrm{v}$ geomanitnom i atmosfernom elektrichestve po nabliudeniam na arch Spitsbergen. Geomagn Aeron 32(2):41-48

Kleimenova NG, Michnowski S, Nikiforova NN, Kozyreva OV (1995) Dlinnoperiodnye geomagnitnye pul'satsii i fluktuatsii napriazhennosti elektricheskogo pola atmosfery na shirotah polyarnogo kaspa. Geomagn Aeron 35(4):38-48

Kleimenova NG, Nikiforova NN, Kozyreva OV, Michnowski S (1996) Long-period geomagnetic pulsations and fluctuations of the atmospheric electric field intensity at the polar cusp latitudes. Geomagn Aeron 35(4):469-477

Kleimenova NG, Michnowski S, Nikiforova NN, Kozyreva OV (1998) Variations of atmospheric electric field vertical component at the evening sector of polar latitudes (obs. Hornsund). Geomagn Aeron 38(6):149-156

Kleimenova NG, Kozyreva OV, Michnowski S, Kubicki M (2008a) Effect of magnetic storms in variations in the atmospheric electric field at midlatitudes. Geomagn Aeron 48(5):622-630. https://doi.org/10. 1134/S0016793208050071

Kleimenova NG, Kozyreva OV, Michnowski S, Kubicki M, Nikiforova NN (2008b) Magnetic storm effects in the atmospheric electric field variations. In: Proceedings of 7th International conference on problems of geocosmos, 26-30 May 2008, St. Petersburg, Russia, pp 123-128 
Kleimenova N, Kozyreva O, Kubicki M, Michnowski S (2009) Variations of mid-latitude atmospheric electric field (Ez) associated with geomagnetic disturbances and Forbush decreases of cosmic rays. Publ Inst Geophys Pol Acad Sci 412(D-73):55-64

Kleimenova NG, Kozyreva OV, Kubicki M, Michnowski S (2010) Morning polar substorms and variations in the atmospheric electric field. Geomagn Aeron 50(1):48-57. https://doi.org/10.1134/S001679321 0010068

Kleimenova NG, Kozyreva OV, Kubicki M, Michnowski S (2011) Variations in the near-ground electric field at high latitudes and the potential drop across the polar cap during morning polar substorms. Geomagn Aeron 51(3):394-401. https://doi.org/10.1134/S0016793211030091

Kleimenova NG, Kozyreva OV, Kubicki M, Odzimek A, Malysheva LM (2012) Effect of substorms in the Earth's nightside sector on variations in the surface atmospheric electric field at polar and equatorial latitudes. Geomagn Aeron 52(4):467-473. https://doi.org/10.1134/S001679321204007X

Kleimenova NG, Kozyreva OV, Michnowski S, Kubicki M (2013) Influence of geomagnetic disturbances on atmospheric elctric field (Ez) variations at high and middle latitudes. J Atmos Sol Terr Phys 99:117122. https://doi.org/10.1016/j.jastp.2012.07.009

Kleimenova NG, Kubicki M, Odzimek A, Malysheva LM, Gromova LI (2017) Effects of geomagnetic disturbances in daytime variations of the atmospheric electric field in polar regions. Geomagn Aeron 57(3):266-273. https://doi.org/10.1134/S0016793217030070

Kobylinski Z, Michnowski S (2007) Atmospheric electric and electromagnetic field rapid changes as possible precursors of earthquakes and volcano eruption: a brief review. Sun Geosph 2(1):43-47

Koskinen HEJ, Baker DN, Balogh A, Gombosi T, Veronig A, von Steiger R (2017) Achievements and challenges in the science of space weather. Space Sci Rev 212:1137-1157. https://doi.org/10.1007/ s11214-017-0390-4

Kotikov A, Frank-Kamenetsky A, Latov Y, Troshichev O, Shishkina E, Murphree J, Elphinstone R (1993) Filamentary structure of the westward electrojet in the midnight sector auroral distribution during substorms: comparison with Viking auroral observations. J Atmos Terr Phys 55(14):1763-1774. https://doi.org/10.1016/0021-9169(93)90143-M

Kozyreva OV, Nikiforova NN, Kleimenova NG, Michnowski S, Kubicki M (2007) Electric air-Earth vertical current pulsations at Hornsund during polar substorms: case study. In: Proceedings of the 13th International conference on atmospheric electricity, 13-17 August 2007, vol I, Beijing, China, pp 29-32

Kubicki M (2002) Results of atmospheric electricity and meteorological observations at S. Kalinowski Geophysical Observatory at Świder, 2001. Publ Inst Geophys Pol Acad Sci 342(D-58)

Kubicki M, Michnowski S, Myslek-Laurikainen B (2007) Seasonal and daily variations of atmospheric electricity parameters registered at the Geophysical Observatory at Świder Poland during 1965-2000. In: Proceedings of the 13th International conference on atmospheric electricity, 13-17 August 2007, vol I, Beijing, China, pp 50-53

Kubicki M, Odzimek A, Kleimenova NG, Kozyreva OV, Neska M (2014) Synchronization of main global electric circuit generators from ground-level electric field Ez at three distant locations on the globe at middle and high latitudes. In: Proceedings of the 15th International conference on atmospheric electricity, 21-26 June 2014, Norman, USA. http://www.nssl.noaa.gov/users/mansell/icae2014/preprints/ Kubicki_140.pdf

Kubicki M, Odzimek A, Neska M (2016) Relationship of ground-level aerosol concentration and atmospheric electric field at three observation sites in the Arctic, Antarctic and Europe. Atmos Res 178179:329-346. https://doi.org/10.1016/j.atmosres.2016.03.029

Kuijpers J, Frey HU, Fletcher L (2015) Electric current circuits in astrophysics. Space Sci Rev 188(1):3-57. https://doi.org/10.1007/s11214-014-0041-y

Lam MM, Tinsley BA (2016) Solar wind-atmospheric electricity-cloud microphysics connections to weather and climate. J Atmos Sol Terr Phys 149:277-290. https://doi.org/10.1016/j.jastp.2015.10.019

Lam MM, Freeman MP, Jackman CM, Rae IJ, Kalmoni NME, Sandhu JK, Forsyth C (2019) How well can we estimate Pedersen conductance from the THEMIS white-light all-sky cameras? J Geophys Res Space 124(4):2920-2934. https://doi.org/10.1029/2018JA026067

Leonovich A, Mazur V (1990) An electromagnetic field, induced in the ionosphere and atmosphere and on the Earth's surface by low-frequency Alfven oscillations of the magnetosphere: general theory. Planet Space Sci 39(4):529-546. https://doi.org/10.1016/0032-0633(91)90048-F

Lester M (2003) Ionospheric convection and its relevance for space weather. Adv Space Res 31(4):941-950. https://doi.org/10.1016/S0273-1177(02)00790-1

Lester M (2008) SuperDARN: an example of a network approach to geospace science in the twenty-first century. J Atmos Sol Terr Phys 70(18):2309-2323. https://doi.org/10.1016/j.jastp.2008.08.003

Lester M (2013) The Super Dual Auroral Radar Network (SuperDARN): an overview of its development and science. Adv Polar Sci 24(1):1-11. https://doi.org/10.3724/SP.J.1085.2013.00001 
Lobodin TV, Paramonov NA (1972) Variation of atmospheric electric field during aurorae. Pure Appl Geophys 100(1):167-173. https://doi.org/10.1007/BF00880237

Loewe CA, Prolss GW (1997) Classification and mean behavior of magnetic storms. J Geophys Res Space 102(A7):14209-14213. https://doi.org/10.1029/96JA04020

Losakiewicz A, Drzewiecki J (1991) On the measurement of the vertical air-Earth current at Spitsbergen and in Poland. In: Michnowski S, Ruhnke LH (eds) Proceedings of the International workshop on global atmospheric electricity measurements, 10-16 September 1989, Madralin, Poland, Publ Inst Geophys Pol Acad Sci 238(D-35):97-107

Love J, Chulliat A (2013) An international network of magnetic observatories. EOS Trans AGU 94(42):373-384

Lukianova RY, Kruglov AA, Frank-Kamenetskii AV, Kotikov AL, Burns GB, French VDR (2011) Relationship between the ionospheric potential and the ground-level electric field in the southern polar cap. Geomagn Aeron 51(3):383-393. https://doi.org/10.1134/S0016793211030121

Marianiuk J, Neska M, Reda J (2007) Results of geomagnetic observations - Belsk Geophysical Observatory 2005. Publ Inst Geophys Pol Acad Sci 392(C-96)

Marianiuk J, Neska M, Reda J (2005) Results of geomagnetic observations, Belsk Geophysical Observatory 2004. Publ Inst Geophys Pol Acad Sci 379(C-92)

Markson R (1978) Solar modulation of atmospheric electrification and possible implications of the Sunweather relationship. Nature 273:103-109. https://doi.org/10.1038/273103a0

Matveev MI, Portyansky AN, Filippov AK (1981) Ionosperic electric fields in the Earth's atmosphere. Issled Geomagn Aeron Fiz Sol 55:105-109

Matveev MI, Portyansky AN, Lunyushkin SB (1982) Analysis of high-latitude geomagnetic effects in atmospheric electricity. Issled Geomagn Aeron Fiz Sol 57:147-152

Michnowski S (1998) Solar wind influences on atmospheric electricity variables in polar regions. J Geophys Res Atmos 103(D12):13939-13948. https://doi.org/10.1029/98JD01312

Michnowski S, Nikiforova NN (1996) Long-period fluctuations of geomagnetic and atmospheric-electric field Hornsund during substorms and other magnetic disturbances. Prz Geof 41(1-2):57-65

Michnowski S, Szymanski A, Nikiforova NN, Kozyreva OV, Ermolenko D, Zielkowski K (1991) On simultaneous observations of geomagnetic and atmospheric electric field changes in Arctic Station Hornsund, Spitsbergen. In: Michnowski S, Ruhnke LH (eds) Proceedings of the International workshop on global atmospheric electricity measurements, 10-16 September 1989, Madralin, Poland, Publ Inst Geophys Pol Acad Sci 238(D-35):83-96

Michnowski S, Nikiforova NN, Kleimenova NG (1996) Remarks on observations of the solar wind influences on the electric field measured at the Earth's surface. In: Proceedings of the 10th International conference on atmospheric electricity, 19-24 June 1996, Osaka, Japan, pp 516-519

Michnowski S, Kubicki M, Kleimenova N, Nikiforova N, Kozyreva O, Israelsson S (2007) The polar ground-level electric field and current variations in relation to solar wind changes. In: Proceedings of the 13th International conference on atmospheric electricity, 13-17 August 2007, vol I, Beijing, China, pp 9-12

Michnowski S, Odzimek A, Kleimenova N, Kozyreva O, Kubicki M, Nikiforova NN (2014) Review of examples of solar wind lower atmosphere coupling observed in the electric field (Ez) variations at the Earth's surface during magnetic storms. In: Proceedings of the 15th International conference on atmospheric electricity, 21-26 June 2014, Norman, USA. http://www.nssl.noaa.gov/users/mansell/ icae2014/preprints/Michnowski_185.pdf

Milan SE (2013) Modeling Birkeland currents in the expanding/contracting polar cap paradigm. J Geophys Res Space 118(9):5532-5542. https://doi.org/10.1002/jgra.50393

Milan SE (2015) Sun et Lumiére: solar wind-magnetosphere coupling as deduced from ionospheric flows and polar auroras. In: Cowley SWH, Southwood D, Mitton S (eds) Magnetospheric plasma physics: the impact of Jim Dungey's research. Springer, Berlin, pp 33-64

Milan SE, Clausen LBN, Coxon JC, Carter JA, Walach MT, Laundal K, Ostgaard N, Tenfjord P, Reistad J, Snekvik K, Korth H, Anderson BJ (2017) Overview of solar wind-magnetosphere-ionosphereatmosphere coupling and the generation of magnetospheric currents. Space Sci Rev 206(1):547-573. https://doi.org/10.1007/s11214-017-0333-0

Mironova IA, Aplin KL, Arnold F, Bazilevskaya GA, Harrison RG, Krivolutsky AA, Usoskin IG (2015) Energetic particle influence on the Earth's atmosphere. Space Sci Rev 194:1-96

Morley SK (2020) Challenges and opportunities in magnetospheric space weather prediction. Space Weather 18(3):e2018SW002108. https://doi.org/10.1029/2018SW002108

Morozov VN, Troshichev OA (2008) Simulation of variations in the polar atmospheric electric field related to the magnetospheric field-aligned currents. Geomagn Aeron 48(6):727-736. https://doi.org/10. 1134/S0016793208060054 
Märcz F (1997) Short-term changes in atmospheric electricity associated with Forbush decreases. J Atmos Sol Terr Phys 59(9):975-982. https://doi.org/10.1016/S1364-6826(96)00076-4

Neska M, Reda J, Wójcik S (2012a) Results of geomagnetic observations; Belsk, Hel, Hornsund, 2010. Publ Inst Geophys Pol Acad Sci 414(C-104). https://pub.igf.edu.pl/results-of-geomagnetic-observationsbelsk-hel-hornsund-2010,4,en,pubs,4,0,3,33.html

Neska M, Reda J, Wójcik S (2012b) Results of geomagnetic observations; Belsk, Hel, Hornsund, 2011. Publ Inst Geophys Pol Acad Sci 415(C-105). https://pub.igf.edu.pl/results-of-geomagnetic-observatio ns-belsk-hel-hornsund-2011,4,en,pubs,4,0,3,34.html

Newell PT, Feldstein YI, Galperin YI, Meng CI (1996) Morphology of nightside precipitation. J Geophys Res Space 101(A5):10737-10748. https://doi.org/10.1029/95JA03516

Newell PT, Sotirelis T, Ruohoniemi JM, Carbary JF, Liou K, Skura JP, Meng CI, Deehr C, Wilkinson D, Rich FJ (2002) OVATION: oval variation, assessment, tracking, intensity, and online nowcasting. Ann Geophys 20(7):1039-1047. https://doi.org/10.5194/angeo-20-1039-2002

Nicoll KA, Harrison RG (2014) Detection of lower tropospheric responses to solar energetic particles at midlatitudes. Phys Rev Lett 112:225001. https://doi.org/10.1103/PhysRevLett.112.225001

Nikiforova NN, Michnowski M (1977) Comparison of geomagnetic and atmospheric electric field variations based on data from Swider and Belsk observatory. In: Dolezalek H, Reiter R, Landsberg H (eds) Electrical processes in atmospheres, Proceedings of the 5th International conference on atmospheric electricity, Garmisch-Partenkirchen, Germany, 2-7 September 1974, Steinkopff, Heidelberg, pp 728735. https://doi.org/10.1007/978-3-642-85294-7_117

Nikiforova NN, Kleimenova NG, Kozyreva OV, Kubicki M, Michnowski S (2002) Polar cap atmospheric electric field response to the sudden commencement of the Bastille Day magnetic storm. In: Book of abstracts of 4th International conference on problems of geocosmos, 3-8 June 2002, St. Petersburg, Russia, p 58

Nikiforova NN, Kleimenova NG, Kozyreva OV, Kubicki M, Michnowski S (2003) Influence of auroral latitude precipitations of energetic electrons on variations in the atmospheric electric field at polar latitudes (Spitsbergen Archipelago). Geomagn Aeron 43(4):29-35

Nikiforova NN, Kleimenova NG, Kozyreva OV, Kubicki M, Michnowski S (2005) Unusual variations in the atmospheric electric field during the main phase of the strong magnetic storm of October 30, 2003, at Świder Polish midlatitude observatory. Geomagn Aeron 45(1):140-144

Nikiforova NN, Teisseyre KP, Michnowski S, Kubicki M (2007) On atmospheric electric field anomaly before the Carpathian earthquake of 30.08.1986 at the Polish observatory Świder. In: Proceedings of the 13th International conference on atmospheric electricity, 13-17 August 2007, vol I, Beijing, China, pp 37-40

Nishitani N, Ruohoniemi JM, Lester M, Baker JBH, Koustov AV, Shepherd SG, Chisham G, Hori T, Thomas EG, Makarevich RA, Marchaudon A, Ponomarenko P, Wild JA, Milan SE, Bristow WA, Devlin J, Miller E, Greenwald RA, Ogawa T, Kikuchi T (2019) Review of the accomplishments of mid-latitude Super Dual Auroral Radar Network (SuperDARN) HF radars. Prog Earth Planet Sci. https://doi.org/10.1186/s40645-019-0270-5

Nowozyński K, Ernst T, Jankowski J (1991) Adaptive smoothing method for computer derivation of K-indices. Geophys J Int 104(1):85-93. https://doi.org/10.1111/j.1365-246X.1991.tb02495.X

Odzimek A (2019a) Polar regions in the Earth's global atmospheric electric circuit research. Prz Geof 64(12):35-72. https://doi.org/10.32045/PG-2019-007

Odzimek A (2019b) SuperDARN in Poland-opportunity for atmospheric science research. Prz Geof 64(34):267-286. https://doi.org/10.32045/PG-2019-009

Odzimek A, Kubicki M, Lester M, Grocott A (2011) Relation between the SuperDARN ionospheric potential and ground electric field at polar station Hornsund. In: Proceedings of the 14th International conference on atmospheric electricity, 8-12 August 2011, Rio de Janeiro, Brazil

Ogilvie KW, Desch MD (1997) The WIND spacecraft and its early scientific results. Adv Space Res 20(4):559-568. https://doi.org/10.1016/S0273-1177(97)00439-0

Olson D (1971) The evidence for auroral effects on atmospheric electricity. Pure Appl Geophys 84(1):118138. https://doi.org/10.1007/BF00875461

Papitashvili VO, Belov BA, Faermark DS, Feldstein YI, Golyshev SA, Gromova LI, Levitin AR (1994) Electric potential patterns in the northern and southern polar regions parameterized by the interplanetary magnetic field. J Geophys Res Space 99(A7):13251-13262

Papitashvili N, Bilitza D, King J (2014) OMNI: a description of near-Earth solar wind environment. In: Abstracts of 40th COSPAR scientific assembly, 2-10 August 2014, Moscow, Russia, C0.1-12-14

Park CG (1976a) Downward mapping of high-latitude ionospheric electric fields to the ground. J Geophys Res 81(1):168-174. https://doi.org/10.1029/JA081i001p00168 
Park CG (1976b) Solar magnetic sector effects on the vertical atmospheric electric field at Vostok, Antarctica. J Geophys Res 3(8):475-478. https://doi.org/10.1029/GL003i008p00475

Park CG, Dejnakarintra M (1977) The effects of magnetospheric convection on atmospheric electric fields in the polar cap. In: Dolezalek H, Reiter R, Landsberg H (eds) Electrical processes in atmospheres, Proceedings of the 5th International conference on atmospheric electricity, Garmisch-Partenkirchen, Germany, 2-7 September 1974, Steinkopff, Heidelberg, pp 536-543. https://doi.org/10.1007/978-3642-85294-7_83

Pfaff RF (2012) The near-Earth plasma environment. Space Sci Rev 168:23-112. https://doi.org/10.1007/ s11214-012-9872-6

Pumpyan PE, Chernysheva SP, Sheftel VM, Yaroshenko AN (1987) Solar-atmospheric effects in variations in the high-latitude atmospheric electric field. Geomagn Aeron 27(2):287-292

Raeder J, Lu G (2005) Polar cap potential saturation during large geomagnetic storms. Adv Space Res 36(10):1804-1808. https://doi.org/10.1016/j.asr.2004.05.010

Raina BN (1991) Modulation of global electric circuit by extra-terrestrial influences. In: Michnowski S, Ruhnke LH (eds) Proceedings of the International workshop on global atmospheric electricity measurements, 10-16 September 1989, Madralin, Poland, Publ Inst Geophys Pol Acad Sci 238(D-35):33-46

Rao M (1970) On the possible influence of the magnetic activity on the atmospheric electric parameters. J Atmos Terr Phys 32(8):1431-1437. https://doi.org/10.1016/0021-9169(70)90103-0

Rasson JL (2007) Observatories, INTERMAGNET. In: Gubbins D, Herrero-Bervera E (eds) Encyclopedia of geomagnetism and paleomagnetism. Springer, Dordrecht, pp 715-717. https://doi.org/10.1007/ 978-1-4020-4423-6_227

Reda J, Neska M (2016) The one second data collection system in Polish geomagnetic observatories. J Ind Geophys Union Spec Issue 2:62-66

Reda J, Neska M, Wójcik S (2008) Results of geomagnetic observations; Belsk, Hel, Hornsund, 2007. Publ Inst Geophys Pol Acad Sci 408(C-101). https://pub.igf.edu.pl/results-of-geomagnetic-observationsbelsk-hel-hornsund-2007,4,en,pubs,4,0,3,29.html

Reda J, Neska M, Wójcik S (2009) Results of geomagnetic observations; Belsk, Hel, Hornsund, 2008, Publ Inst Geophys Pol Acad Sci 409(C-102). https://pub.igf.edu.pl/results-of-geomagnetic-observationsbelsk-hel-hornsund-2008,4,en,pubs,4,0,3,28.html

Reda J, Neska M, Wójcik S (2010) Results of geomagnetic observations; Belsk, Hel, Hornsund, 2009. Publ Inst Geophys Pol Acad Sci 413(C-103). https://pub.igf.edu.pl/results-of-geomagnetic-observationsbelsk-hel-hornsund-2009,4,en,pubs,4,0,3,32.html

Richmond AD (1992) Assimilative mapping of ionospheric electrodynamics. Adv Space Res 12(6):59-68. https://doi.org/10.1016/0273-1177(92)90040-5

Roble RG, Hays PB (1979) A quasi-static model of global atmospheric electricity 2. Electrical coupling between the upper and lower atmosphere. J Geophys Res Space 84(A12):7247-7256. https://doi.org/ 10.1029/JA084iA12p07247

Ruohoniemi J, Baker K (1998) Large-scale imaging of high-latitude convection with Super Dual Auroral Radar Network HF observations. J Geophys Res 103(A9):20797-20811. https://doi.org/10.1029/ 98JA01288

Rycroft MJ, Israelsson S, Price C (2000) The global atmospheric electric circuit, solar activity and climate change. J Atmos Sol Terr Phys 62(17-18):1563-1576. https://doi.org/10.1016/S1364-6826(00) 00112-7

Rycroft MJ, Harrison RG, Nicoll KA, Mareev EA (2008) An overview of Earth's global electric circuit and atmospheric conductivity. Space Sci Rev 137(1):83-105. https://doi.org/10.1007/s11214-008-9368-6

Sao K (1967) Correlation between solar activity and the atmospheric potential gradient at the earth's surface in the polar regions. J Atmos Terr Phys 29(2):213-215. https://doi.org/10.1016/0021-9169(67) 90135-3

Shaw GE, Hunsucker RD (1977) A study of possible correlation between fair-weather electric field and auroral activity. In: Dolezalek H, Reiter R, Landsberg HE (eds) Electrical processes in atmospheres, Proceedings of the 5th International conference on atmospheric electricity, Garmisch-Partenkirchen, Germany, 2-7 September 1974, Steinkopff, Heidelberg, pp 576-581

Sheftel VM (1991) Effects of magnetosphere-ionosphere generators and solar flares on the atmospheric electricity of high latitudes. In: Michnowski S, Ruhnke LH (eds) Proceedings of the International workshop on global atmospheric electricity measurements, 10-16 September 1989, Madralin, Poland, Publ Inst Geophys Pol Acad Sci 238(D-35):23-33

Sheftel V, Bandilet O, Chernysheva S (1992) Effects of planetary magnetic storms in the atmospheric electric field near the Earth's surface. Geomagn Aeron 32(1):186-188 
Sheftel VM, Bandilet OI, Yaroshenko AN, Chernyshev AK, Few AA, Geis PB (1994) Space-time structure and reasons of global, regional, and local variations of atmospheric electricity. J Geophys Res Atmos 99(D5):10797-10806. https://doi.org/10.1029/93JD02857

Siscoe GL, Erickson GM, Sonnerup BUA, Maynard NC, Schoendorf JA, Siebert KD, Weimer DR, White WW, Wilson GR (2002) Hill model of transpolar potential saturation: comparisons with MHD simulations. J Geophys Res Space. https://doi.org/10.1029/2001JA000109

Sotirelis T, Newell PT (2000) Boundary-oriented electron precipitation model. J Geophys Res Space 105(A8):18655-18673. https://doi.org/10.1029/1999JA000269

Stauning P, Clauer CR, Rosenberg TJ, Friis-Christensen E, Sitar R (1995) Observations of solar-winddriven progression of interplanetary magnetic field by-related dayside ionospheric disturbances. J Geophys Res Space 100(A5):7567-7585. https://doi.org/10.1029/94JA01825

Stone EC, Frandsen AM, Mewaldt RA, Christian ER, Margolies D, Ormes JF, Snow F (1998) The advanced composition explorer. Space Sci Rev 86(1):1-22. https://doi.org/10.1023/A:1005082526237

Tanaka Y, Ogawa T, Kodama M (1977) Stratospheric electric fields and currents measured at Syowa Station, Antarctica-1. The vertical component. J Atmos Terr Phys 39(4):523-529. https://doi.org/10. 1016/0021-9169(77)90161-1

Tanskanen EI (2009) A comprehensive high-throughput analysis of substorms observed by image magnetometer network: years 1993-2003 examined. J Geophys Res Space. https://doi.org/10.1029/2008J A013682

Tanskanen E, Pulkkinen TI, Koskinen HEJ, Slavin JA (2002) Substorm energy budget during low and high solar activity: 1997 and 1999 compared. J Geophys Res Space. https://doi.org/10.1029/2001JA9001 53

Teisseyre R (1997) Generation of electric field in an earthquake preparation zone. Ann Geophys Italy 40(3):297-304. https://doi.org/10.4401/ag-3912

Teisseyre R, Nagahama H (2001) Electric and electromagnetic fields related to earthquake formation. In: Majewski E, Teisseyre R (eds) Earthquake thermodynamics and phase transformations in the Earth's interior. Academic Press, Cambridge, pp 535-552

Tinsley BA (1994) Solar wind mechanism suggested for weather and climate change. Eos Trans AGU 75(32):369-374. https://doi.org/10.1029/94EO01010

Tinsley BA (1996) Correlations of atmospheric dynamics with solar wind-induced changes of air-Earth current density into cloud top. J Geophys Res Atmos 101(D23):29701-29714. https://doi.org/10.1029/ 96JD01990

Tinsley BA (2000) Influence of the solar wind on the global electric circuit, and inferred effects on cloud microphysics, temperature, and dynamics in the troposphere. Space Sci Rev 94(1):231-258. https:// doi.org/10.1023/A:1026775408875

Tinsley BA, Heelis RA (1993) Correlations of atmospheric dynamics with solar activity evidence for a connection via the solar wind, atmospheric electricity, and cloud microphysics. J Geophys Res Atmos 98(D6):10375-10384. https://doi.org/10.1029/93JD00627

Tinsley BA, Liu W, Rohrbaugh RP, Kirkland MW (1998) South pole electric field responses to overhead ionospheric convection. J Geophys Res Atmos 103(D20):26137-26146. https://doi.org/10.1029/ 98JD02646

Troshichev OA (2004) Plasma pressure and the field-aligned currents in the magnetosphere. Adv Space Res 33(5):729-736. https://doi.org/10.1016/S0273-1177(03)00637-9

Troshichev OA, Janzhura AS, Stauning P (2007) Magnetic activity in the polar caps: relation to sudden changes in the solar wind dynamic pressure. J Geophys Res Space 112(A11):A11202. https://doi.org/ 10.1029/2007JA012369

Turski A (1996) A remark concerning electromagnetic nature of long period fluctuations of magnetic and electric field observed at Hornsund. Prz Geof 41(1-2):67-68

van der Schueren A, Koenigsfeld L (1963) Electricite atmospherique a la Base Roi Baudoin. Publ Inst Roy Meteorol Belg Serie A 40

Victor NJ, Panneerselvam C, Kumar ACP (2015) Variation of surface electric field during geomagnetic disturbed period at Maitri, Antarctica. J Earth Syst Sci 124(8):1721-1733

Volland H (1972) Mapping of the electric field of the Sq current into the lower atmosphere. J Geophys Res 77(10):1961-1965. https://doi.org/10.1029/JA077i010p01961

Walach MT, Grocott A (2019) SuperDARN observations during geomagnetic storms, geomagnetically active times, and enhanced solar wind driving. J Geophys Res Space 124(7):5828-5847. https://doi. org/10.1029/2019JA026816

Warzecha S (1991) Variations of the electric field and air conductivity at Świder in years 1958-1985. In: Michnowski S, Ruhnke LH (eds) Proceedings of the International workshop on global atmospheric 
electricity measurements, 10-16 September 1989, Madralin, Poland, Publ Inst Geophys Pol Acad Sci 238(D-35):193-197

Warzecha S (1996) Électricité atmosphérique et météorologie Observatoire Géophysique de S. Kalinowski a Świder 1995, Publ Inst Geophys Pol Acad Sci 290(D-47)

Weimer DR (1996) A flexible, IMF dependent model of high-latitude electric potentials having "space weather' applications. Geophys Res Lett 23(18):2549-2552. https://doi.org/10.1029/96GL02255

Weimer DR (2005a) Improved ionospheric electrodynamic models and application to calculating joule heating rates. J Geophys Res Space. https://doi.org/10.1029/2004JA010884

Weimer DR (2005b) Predicting surface geomagnetic variations using ionospheric electrodynamic models. J Geophys Res Space. https://doi.org/10.1029/2005JA011270

Williams ER (2009) The global electrical circuit: a review. Atmos Res 91(2-4):140-152. https://doi.org/10. 1016/j.atmosres.2008.05.018

Williams E, Mareev E (2014) Recent progress on the global electrical circuit. Atmos Res 135-136:208-227. https://doi.org/10.1016/j.atmosres.2013.05.015

Willis DM (1976) The energetics of sun-weather relationships: magnetospheric processes. J Atmos Terr Phys 38(7):685-698. https://doi.org/10.1016/0021-9169(76)90107-0

Wilson CTR (1909) On thunderstorm electricity. Philos Mag 17(100):634-641. https://doi.org/10.1080/ 14786440408636636

Wilson CTR (1921) Investigation on lightning discharges and on the electric field of thunderstorms. Philos Trans R Soc Lond A 211(582-593):73-115. https://doi.org/10.1098/rsta.1921.0003

Yair Y, Price C, Elhalal G (2013) Response of the fair weather atmospheric electrical current to geomagnetic storms. In: EGU General assembly conference abstracts, EGU2013-2042

Zhdanov RF, Moiseev VG, Novikov M, Frank-Kamenetski AV, Chernysheva SP, Sheftel VM, Yaroshenko AN (1984) Effect of electric fields of magnetospheric convection on variations in the high-latitude atmospheric electric field. Geomagn Aeron 24(5):844-846

Zhdanov RF, Moiseev VG, Novikov M, Sokolov VD, Samsonov SN, Chernysheva SP, Sheftel VM, Yaroshenko AN (1985) Vertical component of the atmospheric electric field during geomagnetic disturbances on the Yakutsk meridian. Geomagn Aeron 25(1):169-171

Zhulin IA, Zemlyanikin GA, Kanonidi KD, Morgunov VA, Osipov NK, Turbin RI, Fedorenko YV, Chernysheva SP, Chetaev DN, Sheftel VM (1977) Auroral effects in slow variations and short-period pulsations in the atmospheric potential gradient of magnetospheric origin. Geomagn Aeron 17(5):879-884

Publisher's Note Springer Nature remains neutral with regard to jurisdictional claims in published maps and institutional affiliations.

\section{Authors and Affiliations}

\section{S. Michnowski ${ }^{5}$ A. Odzimek ${ }^{1}$ (D) N. G. Kleimenova ${ }^{2}$ - O. V. Kozyreva ${ }^{2}$ - M. Kubicki ${ }^{1}$. Z. $\mathrm{Klos}^{3} \cdot$ S. Israelsson ${ }^{4} \cdot$ N. N. Nikiforova ${ }^{6}$}

1 Institute of Geophysics, Polish Academy of Sciences, Ksiecia Janusza 64, 01-452 Warsaw, Poland

2 Schmidt Institute of Physics of the Earth, Russian Academy of Sciences, Bolshaya Gruzinskaya 10-1, Moscow, Russia 123242

3 Space Research Center, Polish Academy of Sciences, Bartycka 18A, 00-716 Warsaw, Poland

4 Geocentrum, Uppsala University, Villavägen 16, 75236 Uppsala, Sweden

5 Warsaw, Poland

6 Moscow, Russia 